\title{
Raman Spectroscopy: An emerging tool in neurodegenerative disease research and diagnosis
}

\author{
George Devitt $^{\dagger}$, Kelly Howard, Amrit Mudher ${ }^{\dagger *}$ and Sumeet Mahajan ${ }^{\S \#^{*}}$ \\ ${ }^{\dagger}$ Centre for Biological Sciences, § Institute for Life Sciences and \#Department of Chemistry, University of Southampton, \\ Highfield Campus, SO17 1BJ, Southampton, United Kingdom. \\ *s.mahajan@soton.ac.uk; a.mudher@soton.ac.uk
}

Keywords: Neurodegenerative disease, fingerprint, Raman Spectroscopy, Surface Enhanced Raman Spectroscopy (SERS), Coherent AntiRaman Scattering (CARS), Stimulated Raman Scattering (SRS), Resonance Raman Spectroscopy (RRS) Raman Optical Activity (ROA).

\begin{abstract}
The pathogenesis underlining many neurodegenerative diseases remains incompletely understood. The lack of effective biomarkers and disease preventative medicine demands the development of new techniques to efficiently probe the mechanisms of disease and to detect early biomarkers predictive of disease onset. Raman spectroscopy is an established technique that allows the label-free fingerprinting and imaging of molecules based on their chemical constitution and structure. While analysis of isolated biological molecules has been widespread in the chemical community, applications of Raman spectroscopy to study clinically relevant biological species, disease pathogenesis and diagnosis have been rapidly increasing since the last decade. The growing number of biomedical applications has shown the potential of Raman spectroscopy for detection of novel biomarkers that could enable the rapid and accurate screening of disease susceptibility and onset. Here we provide an overview of Raman spectroscopy (and related techniques) and their application to neurodegenerative diseases. We further discuss their potential utility in research, biomarker detection and diagnosis. Challenges to routine use of Raman spectroscopy in the context of neuroscience research are also presented.
\end{abstract}

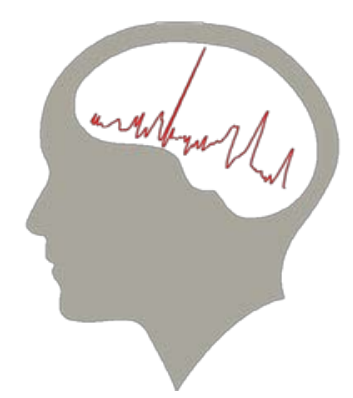

The growing burden of neurodegenerative diseases on society necessitates the development of improved diagnostic and therapeutic strategies. Incidences of age-related disorders including Alzheimer's- and Parkinson's disease have increased as a consequence of improvements in public health and subsequent extensions in lifespan. ${ }^{1,2}$ The level of care required for sufferers adds further economic and social constraints, prompting significant investment into therapeutic research. Despite this, treatments are limited and even diagnosis remains a problem. In order to maximise the efficiency of drug trials it is vital to conclusively identify sufferers at an early stage of disease, which may be years or even decades before the onset of clinical symptoms. Such early identification is a significant challenge. Although much needed for effective disease-preventative medicine, reliable and disease-specific biomarkers have remained elusive. $^{3}$ Therefore, the search for biomarkers for neurodegenerative diseases using different, and novel, physical measurement techniques has continued. Many neurodegenerative diseases have a well characterized pathology based on the observation of protein aggregates. ${ }^{4}$ Such diseases are therefore classified as proteinopathies (also termed protein misfolding diseases and amyloidoses), and each disease is characterized by the aggregation of specific proteins (figure 1). Understanding the structure and function of these proteins both physiologically and pathologically is essential to both fully understand and effectively treat these diseases. Much structural information has come from techniques such as X-ray diffraction (XRD), Nuclear Magnetic Resonance Spectroscopy (NMR), Circular Dichroism (CD) and Fourier Transform Infrared Spectroscopy (FTIR). ${ }^{5}$ Such studies demonstrate that the structure of proteins thought to be causative of neurodegenerative diseases commonly contain significant regions of internal disorder and become $\beta$-sheet rich and insoluble on aggregation. ${ }^{6}$ However, the precise mechanism by which they exert toxicity remains undefined. Current evidence suggests that these misfolded proteins spread across the brain in an ordered way and aggregate in a prion-like manner (e.g. Braak staging in Alzheimer's disease ${ }^{7}$ ), emphasizing the requirement of early therapeutic intervention to halt disease progression. However, early intervention cannot be achieved without a reliable biomarker. Neurodegenerative disease diagnosis is currently based on clinical symptoms, typically through a combination of psychiatric questionnaires (e.g. Mini-Mental State Examination for Alzheimer's disease ${ }^{8}$ ) and biomedical imaging methods including computerised tomography (CT) and magnetic resonance imaging (MRI). ${ }^{9}$ The application of these imaging methods, as well as positron emission tomography (PET), to neurodegenerative disease diagnosis is of growing interest due to an increasing number of potential biomarkers and improving diagnostic accuracy. ${ }^{10}$ Such techniques, however, are slow, subjective, and may not be predictive of disease onset. A perfect diagnosis would be one that is predictive of disease onset, as well as being fast and easy to perform and have an objective interpretation. 
Such a diagnosis would require a reliable biomarker that can be obtained non-invasively (or minimally-invasively). This would ideally be from biofluid, such as a urine or blood sample. Finally, such a biomarker requires a sensitive detection tool. Much research has gone into the development of highly sensitive immunoassay-based detection systems, ${ }^{11}$ but such systems are slow and expensive, as well as reliant on antibody specificity.

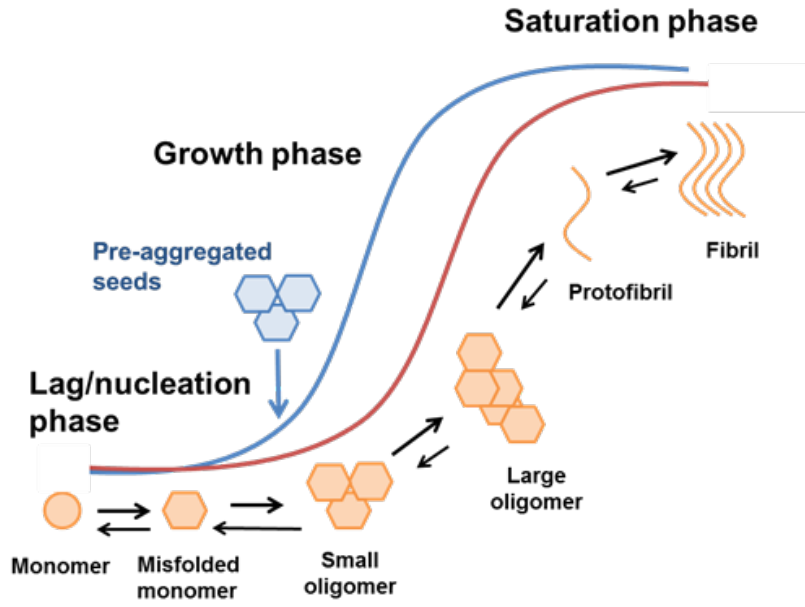

Figure 1 Schematic depicting amyloid formation The protein monomer initially becomes misfolded enabling aggregation into an oligomeric form that acts as a nucleus for further aggregation. This is known as the nucleation phase or the lag phase as the formation of such a nucleus is thermodynamically unfavourable. After the formation of the nucleus, the elongation phase occurs by which oligomers may grow rapidly by the incorporation of monomers or by self-association, followed by the formation of fibrillar protein and saturation. The lag phase can be circumvented by the presence of pre-aggregated seeds/nuclei.

Raman spectroscopy is a reagent- and label-free technique that rapidly provides chemical and structural information by the detection of scattered light from molecules. ${ }^{12,13}$ Each molecule produces a unique 'spectral fingerprint' that is characteristic of its vibrational pattern dependent on its constituent chemical bonds and structure. As protein misfolding and aggregation are central in neurodegenerative disease, Raman spectroscopy provides a powerful analytical tool. Furthermore, changes in complex biological mixtures can also be analysed directly. This is beneficial in diagnostic applications, ${ }^{14-16}$ as differences between healthy and diseased tissue could reveal 'spectral biomarkers' relating to biochemical changes in the early stages of disease. Raman spectroscopy is a non-destructive technique that is not dependent on the state of matter of the sample (e.g. solid, liquid or gas) and does not require labeling for detection. Although Raman spectroscopic techniques typically require limited or no sample preparation, the weak signal acquired from spontaneous Raman spectroscopy is only compatible with bulk materials such as biofluids, meaning that the detection of individual components that are present at biological concentrations may not be possible without sample processing or signal enhancement. Techniques such as Surface Enhanced Raman Spectroscopy (SERS) ${ }^{17}$ and Coherent Anti-Stokes Raman Scattering (CARS) ${ }^{18}$ have been developed to address this issue. This review will cover the principles of Raman spectroscopy, including theoretical and experimental considerations, different Raman scattering based techniques and technologies, and how spectroscopic data is understood and analyzed. The contributions that Raman spectroscopy has made to neurodegenerative disease research will be discussed in the context of protein structure, and how this understanding has been progressed into the development of diagnostic tools. There will be an emphasis on Alzheimer's-, Huntington's-, Parkinson's- and Prion diseases (See table 1). Finally, key challenges and future directions will be discussed.

\section{Raman Spectroscopy}

Principles Inelastic scattering of light due to molecules was first reported by C.V Raman early in the $20^{\text {th }}$ century ${ }^{19}$ and the phenomena was named after him as the 'Raman effect' and such scattered radiation as 'Raman scattering'. The Raman spectroscopy technique, that is the measurement of Raman scattered radiation, provides information about chemical bonding and molecular structure through the detection of photons that are scattered inelastically from a sample using a monochromatic light source, typically a laser. Scattering differs from emission processes e.g. fluorescence, which rely on the excitation of electrons to a higher electronic state through the input of radiation of appropriate energy. The electrons in the higher state typically lose energy to vibrational, collisional and other processes before relaxing back to the ground state and in the process emit a photon with lower energy (higher wavelength) equivalent to the color of light that is seen (Figure 2A). On the other hand, scattering is a process whereby the radiation is not absorbed (albeit for a fraction of typical times involved for absorption processes). The majority of the photons in the incident radiation are scattered without any change in energy, known as Rayleigh/elastic scattering. However, around 1 in 10 million photons can get scattered such that they lose or gain energy to or from the vibrations of a molecule. In the process this inelastically scattered light will have a slightly different energy than the incident light that allows it to be distinguished from Rayleigh scattered light. In the case where energy is lost to a vibration the scattered photon will have a lower energy than the excitation photon and this is termed as 'Stokes Raman scattering'; if it is higher it is termed 'anti-Stokes Raman scattering'. At room temperatures the Stokes Raman scattering process is predominant and therefore usually only that is recorded in typical Raman spectroscopy measurements. The difference in energy between the incident light and the Raman scattered light is equivalent to the frequency of the vibrational bond that is excited. Each chemical bond within a molecule (e.g. C-H, C-O etc.) vibrates at a different frequency and produces a unique signal (see table 2). Plotting the intensity of Raman scattered light detected against these frequencies (typically as Raman shift in $\mathrm{cm}^{-1}$ ) enables a spectrum to be created for the sample. Every molecule has a unique spectrum, also known as a vibrational 'fingerprint'.

While infrared (IR) spectroscopy relies on direct absorption of energy by the vibrational modes in a molecule, information obtained by Raman spectroscopy is complementary to that in IR. Vibrational modes that are weak in IR spectroscopy are typically strong in Raman spectroscopy and vice versa. This is because IR spectroscopy relies on changes in the dipole moment of a molecule, whereas Raman spectroscopy relies on changes in a molecule's polarizablilty. Thus highly polar bonds are strong in IR and weak in Raman. This also results in the major advantage of Raman spectroscopy over IR, as water is an inherently weak Raman scatterer and conversely a very strong IR absorber. Consequently Raman spectroscopy is ideal for analysis of biological samples in their native and/or non-dehydrated states. Figure 2B demonstrates a generic setup for a Raman system. A key consideration is the choice of laser used to excite a sample. Wavelengths from visible to near infrared (NIR) are typically used for biological samples. Lower energy NIR lasers are a good choice as they limit fluorescence, which can be a major interference in Raman spectroscopy measurements. Since Raman 


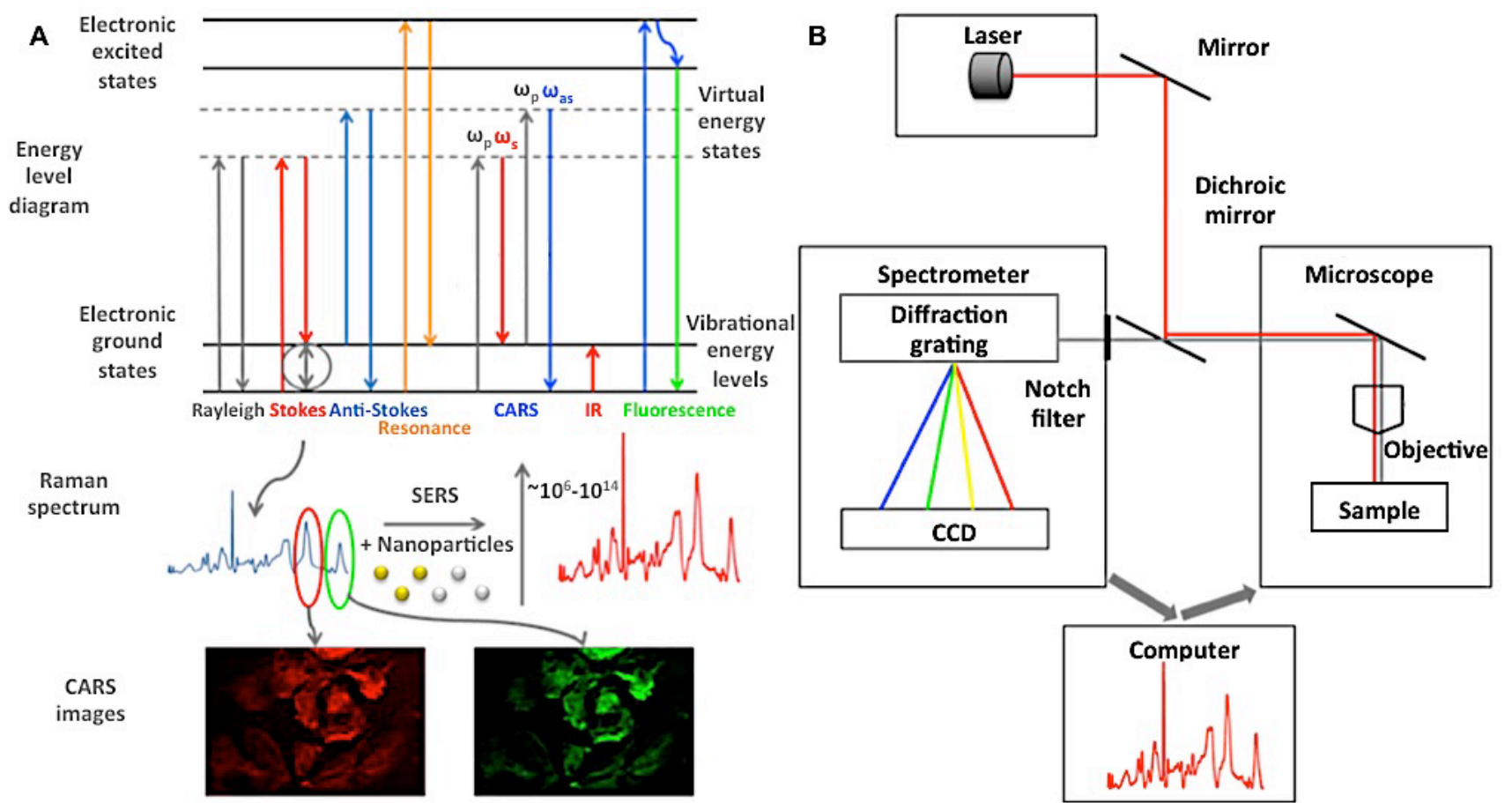

Figure 2. Principle of Raman spectroscopy (A) Energy level diagram depicting (from left to right): Rayleigh scattering, Stokes scattering, anti-Stokes scattering, resonance Raman, coherent anti-stokes Raman spectroscopy (CARS), infrared absorption and fluorescence. Each process is explained further in the main text. (B) Generic setup for a Raman micro-spectroscopy system. Spontaneous Raman scattering is induced using a laser to excite vibrations in molecules. Scattered light is then typically collected at $90^{\circ}$ or $180^{\circ}$ to the sample and Rayleigh scattering can be removed using a filter corresponding to the wavelength of the incident light. Light is then split into individual frequencies by a diffraction grating and converted into electrons by a detector, such as a charge-coupled device (CCD). The spectrometer is coupled to a computer and the digitised information is presented as a spectrum. A Raman spectrometer can be coupled to microscope that enables the focussing of light onto an object.

Table 1. Raman-based techniques discussed in this review

Technique

Spontaneous Raman spectroscopy

Resonance Raman spectroscopy ${ }^{30}$

Raman optical activity ${ }^{31}$

Surface-enhanced Raman spectroscopy ${ }^{26}$

Coherent anti-Stokes Raman scattering ${ }^{28,29}$

Stimulated Raman scattering ${ }^{28,29}$

Polarized Raman ${ }^{20}$
Relative

enhancement

$10^{6}$

$10^{-3}-10^{-5}$

$10^{14}$

$10^{5}$

$10^{5}$

1
Limitations

Weak signal

Fluorescence enhancement

Weak signal

Substrate required

Variability e.g. enhancement hotspots and metal-molecule affinity/binding orientation

Enhancement selection

Non-resonant background Spectral distortion

Single wavelength selection*

Single wavelength selection*

Solid state samples only

*If not using a broadband laser source 
Table 2. Raman peak assignments ${ }^{21-36}$

Note that the peak position can alter depending on the sample, solvent, $\mathrm{pH}$ and temperature.

\begin{tabular}{|c|c|c|c|}
\hline $\begin{array}{lr}\text { Peak } & \text { position } \\
\left(\text { Raman Shift } \mathrm{cm}^{-1}\right)\end{array}$ & Assignment & $\begin{array}{cr}\text { Peak position } \\
\left(\text { Raman Shift } \mathrm{cm}^{-1}\right)\end{array}$ & Assignment \\
\hline 428 & Cholesterol/cholesterol esters & 1255 & Lipids \\
\hline $495-550$ & Disulfide bond (S-S) & $1268-1298$ & Amide III, $\alpha$-helix \\
\hline 484 & Glycogen & $\begin{array}{l}1220-1248 \\
1241-1250\end{array}$ & $\begin{array}{l}\text { Amide III, } \beta \text {-sheet } \\
\text { Amide III, disordered/PPII }\end{array}$ \\
\hline 548 & Cholesterol & 1395 & Haemoglobin \\
\hline 701 & Cholesterol & $1445-1482$ & C-H deformation \\
\hline 665,726 & C-S/cysteine & 1470 & $\mathrm{C}=\mathrm{N}$ \\
\hline 744,757 & Cytochrome C & & \\
\hline 1269,1490 & Histidine & $1550-1564$ & Amide II $\beta$-sheet \\
\hline $\begin{array}{l}620,1000,1030 \\
1175,1580,1604\end{array}$ & Phenylalanine & $1548-1561$ & Amide II disordered/PPII \\
\hline $\begin{array}{l}750,875,1340 \\
1555,1610\end{array}$ & Tryptophan & $1653-1658$ & Amide I $\alpha$-helix \\
\hline $\begin{array}{l}640,830,850,1175,1 \\
210,1580,1615\end{array}$ & Tyrosine & $1665-1675$ & Amide I $\beta$-sheet \\
\hline 810 & C-O-C \& C-C collagen backbone & $1659-1682$ & Amide I disordered/PPII (broad) \\
\hline 843 & Glucose & 1729,1744 & Ester \\
\hline $860,980-1000$ & Phosphate & 2715,2790 & $\mathrm{C}-\mathrm{H}, \mathrm{N}-\mathrm{H}, \mathrm{O}-\mathrm{H}$ \\
\hline $923-958$ & $\mathrm{C}-\mathrm{C}$ & 2840 & Lipid C-H symmetric stretch \\
\hline 927 & Proline/valine & 2870 & Lipid C-H asymmetric stretch \\
\hline 1020 & Glycogen & 2845 & Lipid $\mathrm{CH}_{2}$ \\
\hline 1043 & Carbohydrates,Phosphates & 2884,2930-2955 & Lipid $\mathrm{CH}_{3}$ \\
\hline 1073 & Triglycerides & $2909-2990$ & $\mathrm{C}-\mathrm{H}$ \\
\hline $1121-1145$ & $\mathrm{C}-\mathrm{N}$ & 3200 & $\mathrm{~N}-\mathrm{H}$ \\
\hline 1130 & Fatty acids & 3330 & $\mathrm{O}-\mathrm{H}$ \\
\hline
\end{tabular}


scattering signals are inversely proportional to the $4^{\text {th }}$ power of the wavelength, the signal: noise ratio of NIR lasers can be a limitation when assessing biological material such as proteins, lipids and DNA that exist at low physiological concentrations. For instance compared to a $785 \mathrm{~nm}$ laser a $488 \mathrm{~nm}$ laser will produce $\left(\frac{785}{488}\right)^{4}=6.7$ times higher signal. Furthermore, the sensitivity of typical silicon-based CCD detectors decreases at near-infrared wavelengths $>900 \mathrm{~nm}^{37}$, which can be another issue especially for detecting Stokes Raman signals of vibrational frequencies $>2000 \mathrm{~cm}^{-1}$. Signals in Raman spectroscopy can be further enhanced by using the phenomena of resonance in a technique termed resonance Raman spectroscopy. Essentially the excitation laser matches the energy for an electronic transition in the molecule being investigated and this electronic excitation results in the large enhancement of Raman signals. ${ }^{38}$ However, most organic molecules including proteins have electronic excitation energies in the UV region. Thus by using UV excitation higher signals can be achieved due to both the wavelength dependence and the resonance effect although sample damage becomes a major issue. This technique of UV resonance Raman spectroscopy, while unsuitable for in vivo applications, has been extensively employed for studying proteins and their conformations. ${ }^{35,39-42}$

Multivariate Analysis The Raman spectra of biological molecules contain a wealth of information including chemical and structural composition and environmental conditions. Increases in sample complexity will increase the complexity of information obtained; with the Raman spectrum of a whole cell including contributions from carbohydrates, lipids, proteins and DNA. Therefore, subtle changes in spectral profiles may represent significant biological differences. Reducing the dimension of such complex datasets using multivariate statistical methods can highlight these spectral differences and enable the extraction of this important biological information as described briefly below. For an in-depth review on data handling approaches and multivariate computational analysis used to extract biological information as applicable to vibrational techniques such as infrared and Raman spectroscopy the reader is referred to a comprehensive review by Trevisan et al. ${ }^{43}$

Principle component analysis is an unsupervised method (meaning that data classes are not identified) that reduces complex datasets into a small number of principle components (PCs). These PCs are orthogonal (statistically independent) with PC1 representing the axis on which there is greatest variation between datasets. The following PCs account for the remaining variation between the datasets, with each representing the axis responsible for the next largest variance. Therefore, only a small number of PCs may be required to capture all of the significant variation between the datasets. Each PC can also be expressed as a loading, which represents the coefficient of each wavenumber that is used to transform the original data into the component scores in the new data space. As the loading plot of PC1 contains the Raman features responsible for the most variation between the spectra, further analysis enables the determination of the biological/chemical source of variation between different conditions. ${ }^{44}$

PLS is a data reduction technique that is similar to PCA, but instead enables changes in $\mathrm{Y}$ to be explained by changes in $\mathrm{X}$ through assessing the correlation between these variables. PLS is a supervised method and maximizes the separation of classes as opposed to the overall variance, making PLS useful for smaller datasets. Classification models such as Linear Discriminant Analysis can also be applied to maximize the separation of classes. For example; a PCA-LDA model has been shown to discriminate between normal and colorectal tumor tissue in mice with an accuracy of $86.8 \%$ using a miniaturized Raman endoscope ${ }^{45}$ highlighting the potential of Raman spectroscopy in combination with multivariate statistical models for both classification and diagnosis.

Enhancement and Imaging While Raman spectroscopy is highly informative due to weakness of signals it is not an ideal technique for characterizing low concentrations of materials; this depends on the molecule, for proteins, typically $0.1 \mathrm{mM}$ or above concentrations are required for enough signal from peaks over noise. Thus it is also not suitable for rapid imaging. A number of techniques have therefore been developed to enhance the sensitivity of Raman Spectroscopy. Surface-Enhanced Raman Spectroscopy (SERS) is a technique that uses metallic nanostructures or rough metal surfaces to enhance the Raman signal by several (up to $>10^{12}$ ) orders of magnitude which allows even single molecule detection. ${ }^{46}$ This enables SERS to detect very low concentration ranges and has clear advantages for diagnostic applications. Electromagnetic effects are the predominant cause of SERS enhancement, with some contribution from chemical surface interactions. This chemical enhancement can itself be up to $10-100$ times. $^{46}$ The electromagnetic contribution to enhancement is due to the enhanced electric field induced as a result of collective oscillations of surface electrons, called surface plasmons, excited by the incident electromagnetic radiation. The frequency (or wavelength) at which this surface plasmon can be excited is called surface plasmon resonance (SPR). When this SPR is excited on nanoscale materials resulting in high local fields it can cause enhanced scattering, which is responsible for the enhancements observed in SERS. The resulting enhancement is greatest when this plasmon frequency is matched by the frequency of the incident light. Silver and gold are typically used for SERS experiments as their surface plasmon resonance frequencies fall within the visible and near-IR and therefore are ideal for enhancing the Raman signal. It is common to observe a signal enhancement of $\sim 10^{6}$ in SERS over Raman spectroscopy. However, it is to be noted that only molecules near or on the surface of a plasmonic nanomaterial will experience the enhanced field and hence, signals in SERS are surface selective. Surface selection rules may enhance certain vibrations preferentially over others and also may cause certain vibrational modes to slightly alter due to interaction with the surface leading to small shifts in the vibrational frequencies observed in the SERS spectrum. The shifts depend on the strength of the surface interaction. Thus, peaks in a SERS spectrum can be a smaller subset of that in its Raman spectrum and some peaks may be altered.

Coherent Raman Scattering refers to a set of techniques that use non-linear optics to stimulate vibrations and thus enhance signals. Coherent anti-Stokes Raman scattering (CARS) and stimulated Raman scattering (SRS) are the two major forms of these techniques. Both CARS and SRS are sensitive to the same vibrational signatures as Raman spectroscopy, but use multiple lasers of different wavelength to excite the sample. The sample is first excited to a virtual state using a pump beam $\left(\omega_{p}\right)$, and then a second laser beam, Stokes ( $\omega s)$ is used to set up a coherence targeting the desired vibrational mode. The difference between the laser frequencies must equal the vibrational frequency of the targeted bond vibration such that: $v_{V I B}=v_{P}-v_{S}$, where $v_{\text {VIB }}$ is the vibrational frequency of the bond, $v_{\mathrm{P}}$ is the frequency of the pump beam and vs is the stokes beam frequency. Thus, all molecules in the excited focal volume possessing a vibrational mode at the stimulated frequency will oscillate coherently resulting in an enhanced signal. The Raman scattered signals can be measured by either measuring the loss in pump or gain in 
Stokes photons, both of which will occur when the difference matches a vibrational frequency, and this detection methodology is used in SRS. However, the vibrational coherence can also probed by another laser beam (typically the same as the pump beam) such a blue-shifted anti-Stokes photon ( $\left.\omega_{\mathrm{AS}}\right)$ is scattered such that $\omega_{A S}=2 \omega_{P}-\omega_{S}$ and detected; this detection methodology is used in CARS. By tuning the lasers to different

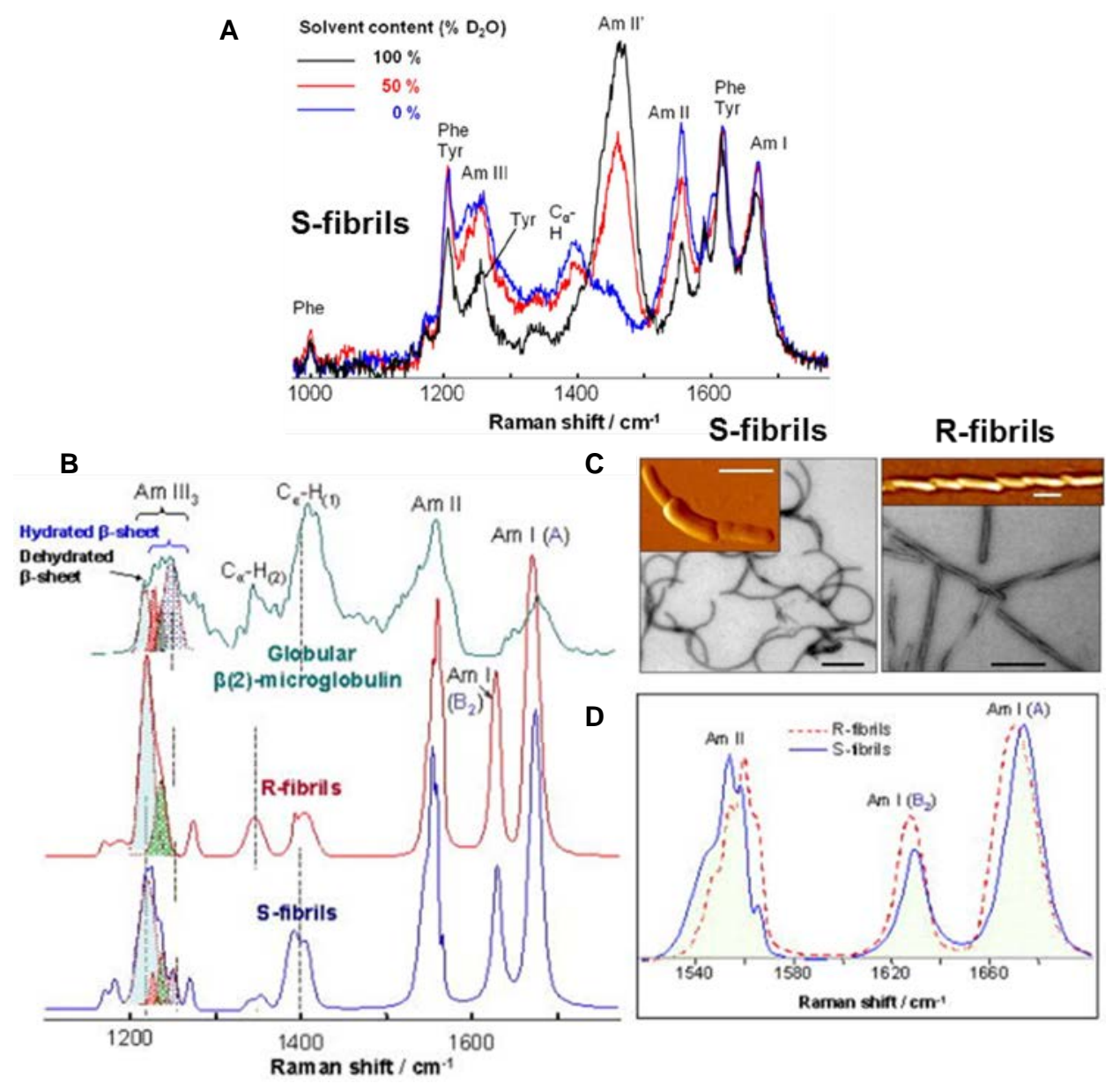

Figure 3 DUVRRS analysis of the cross- $\beta$-core of prion fibril strains (A) DUVRR spectra of S-fibrils in $100 \% \mathrm{D}_{2} \mathrm{O}$ (black trace), $50 \%$ $\mathrm{D}_{2} \mathrm{O} / \mathrm{H}_{2} \mathrm{O}$ (red trace) and $100 \% \mathrm{H}_{2} \mathrm{O}$ (blue trace). Recording the spectrum for each protein in a series $\mathrm{D}_{2} \mathrm{O}$ concentrations enabled the calculation of the cross- $\beta$ core spectra shown in B. (B) Reference spectrum for $\beta 2$-microglobulin with antiparallel $\beta$-sheet secondary structure (green trace), the cross- $\beta$ core of R-fibrils (red trace) and the cross- $\beta$ core of S-fibrils (blue trace). Spectra for the fibrils' cross- $\beta$ cores were determined using the Bayesian approach. (C) EM images and AFM images (inset) of S-fibrils (left) and R-fibrils (right). Scale bars $=0.2 \mu \mathrm{m}$. (D) Amide I and Amide II spectra for the cross- $\beta$ core of R-fibrils (dashed, red trace) and S-fibrils (solid, blue trace). Adapted from Shashilov et al. ${ }^{47}$

frequencies, or by having a broadband laser source, multiple frequencies or spectroscopic SRS or CARS can also be performed. ${ }^{48}$ Both techniques result in enhancement of up to $10^{5}$ times over normal (spontaneous) Raman spectroscopy signals and enable the label-free imaging of specific vibrations based on the distribution of signal intensity within a sample. However, SRS spectra do not display the non-resonant background and spectral distortion that limit the sensitivity of CARS. As the SRS and Raman spectra are identical, Raman spectroscopic data can be applied more effectively for SRS imaging applications than for CARS. ${ }^{49,50}$ As well as signal enhancement, selective sampling techniques have been applied to Raman imaging in order to decrease acquisition times, which is particularly important for live cell or tissue imaging. For example, Kong et al used a selective sampling algorithm to obtain Raman images of the protozoan parasite Neospora caninum and their microenvironment within live cells with a time resolution ten times faster than a raster scan. ${ }^{51}$ High spatial and temporal resolution chemical imaging is necessary to further our understanding of disease mechanisms and also have clear advantages for diagnostic imaging applications. For a summary of the techniques discussed in this review see table 1.

Above we have briefly described a number of Raman based techniques that have been used in a variety of analytical and imaging applications. We now examine their applications specifically in the area of neurodegenerative diseases. The use of Raman spectroscopy for biomedical applications has been reviewed previously. ${ }^{12,}$ 14, 15 The neurodegenerative diseases that we have considered can be classed, in biophysical terms, as, proteinopathies. Each of these diseases has a hallmark pathology resulting from the misfolding and subsequent aggregation of a particular protein. We give a brief overview of each disease and discuss the main results and conclusions from the application of Raman and Raman-based techniques to them. 


\section{Prion Diseases}

Prion diseases, also known as transmissible spongiform encephalopathies (TSEs), are characterised by the misfolding of cellular Prion protein $\left(\mathrm{PrP}^{\mathrm{C}}\right)$ into the pathogenic form $\left(\mathrm{PrP}^{\mathrm{Sc}}\right)$. $\mathrm{PrP}^{\mathrm{Sc}}$ has the curious ability to interact with $\mathrm{PrP}^{\mathrm{C}}$ proteins and "convert" them to $\mathrm{PrP}^{\mathrm{Sc}}$ leading to aggregate formation. The subsequent propagation of such aggregates results in widespread neurodegeneration that manifests symptomatically as both cognitive and motor deficits. ${ }^{52}$ Early FTIR and CD spectroscopic studies revealed that despite no change in primary sequence, the pathological conversion of the prion protein causes an increase in $\beta$-sheet structure and a corresponding decrease in $\alpha$-helical structures, which renders the $\mathrm{PrP}^{\mathrm{Sc}}$ variant resistant to protease degradation. ${ }^{53}$ Interestingly, final amyloid states can also vary in composition and pathogenicity and have been referred to as distinct prion "strains". The structures of morphologically distinct recombinant PrP strain fibrils termed R- and S-fibrils that differ in infectivity were assessed using deuterium exchange UV Raman resonance spectroscopy (UVRRS) (figure 3). ${ }^{47}$ Deuterium exchange is a method whereby covalently bonded hydrogen is replaced by deuterium. This will occur more readily in amide groups when they are exposed to the solvent $\left(\mathrm{D}_{2} \mathrm{O}\right)$, such as regions with a disordered secondary structure, and will lead to a shift in the Amide band obtained from Raman spectroscopy. In the case of amyloid fibrils, the cross- $\beta$-core is made up of highly ordered layers of $\beta$-sheet that is not accessible to the solvent, which will not result in a significant rate of deuterium exchange and thus no change to the Raman spectrum. Notable changes in the Raman spectrum for PrP fibrils after deuterium exchange included a downshift in the Amide II band from $1555 \mathrm{~cm}^{-1}$ to $1450 \mathrm{~cm}^{-1}$ (termed the Amide II' band) and a decrease in the Amide III band intensity. In order to mathematically separate the signal of the fibril core from the surrounding unordered parts of the fibril, a Bayesian approach (Knuth, Bayesian interference for inverse problems, 1998) was used in which known spectral features and concentrations (with $\mathrm{D}_{2} \mathrm{O}$ concentration from $0-100 \%$ used in $10 \%$ increments) were applied to The Bayes theorem. An upshift in the Amide II band and downshift in the Amide I band in the spectrum for the cross- $\beta$-core of S-fibrils demonstrated weaker hydrogen bonding in relation to the R-fibril. It was speculated that the stronger hydrogen bonding within the cross- $\beta$-core of the Rfibril might be related to their greater infectivity, warranting further investigation.

Raman Optical Activity (ROA) is another method based on Raman spectroscopy, but relies on the difference in scattering intensities between left and right circularly polarised light from chiral molecules ${ }^{54}$ and can be considered as complimentary to vibrational CD..$^{55} \mathrm{ROA}$ analysis of a reduced form of mammalian PrP produced Amide I/II bands that closely resembled those for a $\beta$-sheet rich form of poly-l-lysine, and differed from a number of proteins whose native structures are rich in $\beta$-sheet. ${ }^{56}$ This was confirmed through the clustering of the two proteins using PCA. It was suggested that PrP might not share the typical irregular, twisted $\beta$-sheet structure found in native $\beta$-sheet rich proteins, and so contain unusually flat and regular $\beta$-sheets in the C-terminal domain, similar to the structure of $\beta$-sheet poly-l-lysine. The N-terminal domain of $\operatorname{PrP}^{\mathrm{C}}$, on the other hand, is unstructured and contains a number of highly conserved octapeptide repeats (Pro-His-Gly-Gly-Gly-Trp-Gly-Gln). ${ }^{57}$ Mass spectrometry has showed that this region binds to divalent metal ions, particularly $\mathrm{Cu}(\mathrm{II}) .^{58}$ Raman spectroscopy is an appropriate tool for probing metal coordination, as the formation of new bonds leads to measurable changes in the Raman spectrum. Using synthetic PrP fragments, Miura et al presented changes in Raman shift that correlate to the formation of bonds between the imidazole side chain of histidine and $\mathrm{Cu}(\mathrm{II})$ during coordination, with additional contributions from the amide nitrogens of proceeding glycine residues. ${ }^{33,59}$ The affinity of $\mathrm{PrP}$ for $\mathrm{Cu}(\mathrm{II})$ was shown to decrease at weakly acidic $\mathrm{pH}$, which may be important for $\mathrm{Cu}(\mathrm{II})$ transport and reduction. ${ }^{60}$ Weakly acidic $\mathrm{pH}$ also led to a change in $\mathrm{Cu}(\mathrm{II})$ coordination that formed insoluble $\mathrm{Cu}(\mathrm{II})(\mathrm{His}) 4$ complexes that may reflect the formation of $\mathrm{PrP}^{\mathrm{Sc}}$ in the early endosome in prion disease. ${ }^{59}$ Indeed, there is evidence that metal imbalance in the brain may be an early biochemical change prior to the onset of prion disease, ${ }^{61}$ and a ROA study has shown that the presence of $\mathrm{Cu}(\mathrm{II})$ or $\mathrm{Mn}(\mathrm{II})$ during $\mathrm{PrP}^{\mathrm{c}}$ folding leads to the formation of different secondary structures. ${ }^{62}$ Following on from this work, $\mathrm{PrP}-\mathrm{Cu}(\mathrm{II})$ coordination was assessed in cell-based systems seeded onto gold nano-surfaces to provide surface-enhancement of the Raman signal (SERS). Exposing cells to $\mathrm{Cu}$ (II) demonstrated a quantitative relationship between $\mathrm{Cu}(\mathrm{II})$-binding and PrP concentration based on the intensity ratio of Raman peaks corresponding to free and $\mathrm{Cu}(\mathrm{II})$-bound histidine. ${ }^{63,64}$ Measuring changes in $\mathrm{Cu}(\mathrm{II})$ coordination using SERS may be a useful tool for monitoring early-onset prion disease, as the length of the octapeptide repeat is negatively correlated with disease onset, ${ }^{65}$ and PrP that has a high number of octapeptide repeats has altered $\mathrm{Cu}(\mathrm{II})$ binding. ${ }^{66}$

While prion proteins have been studied in vitro, there is only one study to date that has tested the diagnostic potential of Raman spectroscopy for prion disease, specifically in sheep that are naturally susceptible to scrapie infection. ${ }^{67}$ Membrane fractions from the blood of 150 healthy, and 31 scrapie-infected sheep were analysed for the presence of $\beta$-sheet structure in the Amide I region $\left(1670 \mathrm{~cm}^{-1}\right)$ indicating the conversion of $\operatorname{PrP}^{\mathrm{C}}$ to $\mathrm{PrP}^{\mathrm{Sc}}$. Scrapie-infected sheep were diagnosed with $100 \%$ accuracy, as determined by post-mortem analysis. This study also demonstrated that Raman spectroscopy could be used to track disease progression, with further increases in $\beta$-sheet intensity observed after one month of sickness.

\section{Parkinson's Disease}

Parkinson's disease (PD) is characterised by the death of dopaminergic neurons within the substantia nigra, leading to a breakdown of effective muscular control. Eventually, the disease manifests itself in memory and behavioural abnormalities, and can reduce the life expectancy of sufferers. ${ }^{68}$ One of the main pathological markers for PD is the build-up of the protein $\alpha$ synuclein in inclusions called Lewy bodies, believed to have a toxic element that triggers neurodegeneration. ${ }^{69,70} \mathrm{CD}$ studies have shown that monomeric $\alpha$-synuclein exists in a natively unfolded conformation, ${ }^{71-73}$ with NMR studies supporting this secondary structure and suggesting that the $\mathrm{N}$-terminal region has a strong propensity for $\alpha$-helical structure. ${ }^{74}$ ROA spectra of monomeric $\alpha$-synuclein suggest that the secondary structure predominantly consists of polyproline II (PPII) helix, due to the large positive peaks between $1318-1320 \mathrm{~cm} \mathrm{~cm}^{-1}$ and at $1675 \mathrm{~cm}$ $\mathrm{cm}^{-1} .{ }^{75}$ These locally ordered regions within the unordered protein structure lack intrachain hydrogen bonding and provide a static form of disorder, as opposed to the dynamic random coil (although it is argued that all unfolded proteins adopt a PPII conformation ${ }^{76}$ ). This provides a plastic-like property that may be, at least in part, necessary for the structural conversion to $\alpha$-helix or $\beta$-sheet ${ }^{77}$, whilst also making the protein's structure adaptable to its environment and therefore difficult to characterise by traditional methods. Conventional Raman spectroscopy can be used to distinguish random coil and PPII helix conformations, but unlike ROA, spectra can be convoluted by the presence of other secondary structural elements. ${ }^{78}$ Mensch et al demonstrated the structural heterogeneity of $\alpha$-synuclein in different environments 
using ROA. $^{79}$ The spectrum for $\alpha$-synuclein in $10 \%$ TFE $(2,2,2-$ triflurethanol) was consistent with protein aggregation and the formation of $\beta$-sheet, due to the presence of a negative peak at $1662 \mathrm{~cm}^{-1}$ and a positive peak at $1678 \mathrm{~cm}^{-1}$. Interestingly, in $5 \%$ TFE this negative peak was missing from the ROA spectrum (amongst other differences), indicating that the protein may not be aggregated, but rather in a partially folded state that acts as an intermediate for aggregation. However, these clear differences in the ROA spectra were not evident in the Raman spectra for $\alpha$ synuclein in $5 \%$ and $10 \%$ TFE. This provides further evidence
Monomers
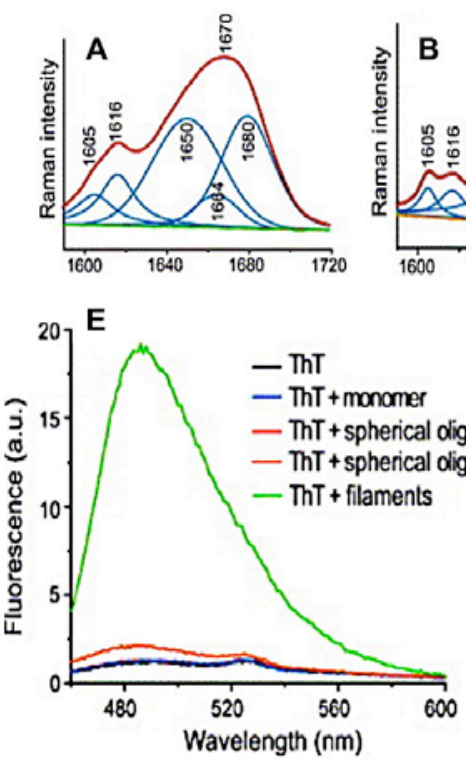

Spheroidal oligomers

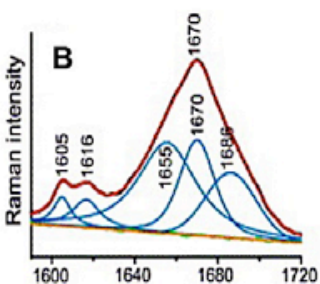

Spheroidal oligomers with protofilaments
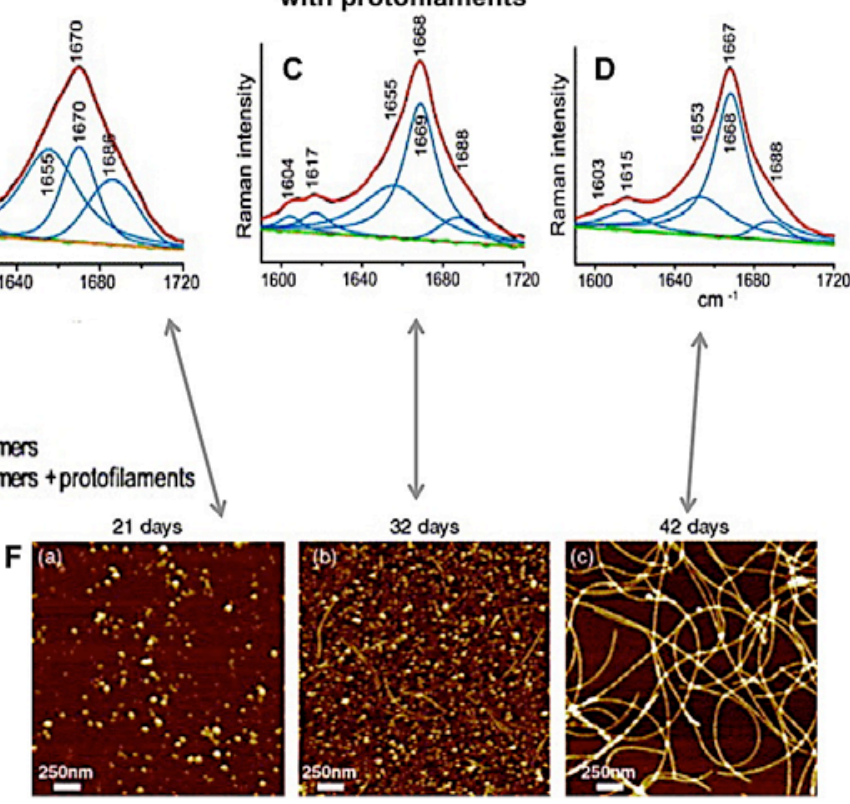

Figure 4 Structural changes of $\boldsymbol{\alpha}$-synuclein during aggregation Raman spectra (A-D) reveal a narrowing of the amide I band with an increase in intensity of the peak $\sim 1670 \mathrm{~cm}^{-1}$, indicating an increase in $\beta$-sheet structures with aggregation. Furthermore, deconvoluted peaks corresponding to $\alpha$-helix $\left(\sim 1650 \mathrm{~cm}^{-1}\right)$ and disorder $\left(\sim 1680 \mathrm{~cm}^{-1}\right)$ also decrease in intensity with aggregation (E) ThT fluorescence spectra only show a large increase in fluorescence on filament addition, despite the high level of $\beta$-sheet detected in the protofilament sample by Raman spectroscopy (F) spheroidal oligomers were observed at 21 days of incubation, with proto-filaments at 32 days and filaments at 42 days of incubation. Adapted from Apetri et al. ${ }^{80}$

that ROA is more sensitive to secondary structural conformations than conventional Raman spectroscopy. Maiti et al used Raman spectroscopy to determine the contribution of secondary structure components to the overall structure of monomeric $\alpha$-synuclein through deconvolution of the Amide I region of $\alpha$-synuclein by fitting three component bands ( $\alpha$-helix $\sim 1650-1656 \mathrm{~cm}^{-1}$, $\beta$-sheet $\sim 1664-1670 \mathrm{~cm}^{-1}$ and unordered $\sim 1680 \mathrm{~cm}^{-1}$ ), as well as bands corresponding to aromatic amino acids. ${ }^{31}$ Interestingly, this analysis estimated that $48 \%$ of the secondary structure is composed of $\alpha$-helix that was not detected using CD. It has been shown previously that UVRRS is able to detect single $\alpha$-helical turns that cannot be detected by $\mathrm{CD},{ }^{39}$ suggesting that $\alpha$-synuclein may consist of short segments of $\alpha$-helical structure as opposed to an extended $\alpha$-helical or disordered conformation. Further analysis of the $\alpha$-synuclein Amide I region during fibrillation revealed the changes in secondary structural components from monomer through to oligomer and aggregate (figure 4). ${ }^{80}$ Individual structural states were obtained through the incubation of monomeric $\alpha$-synuclein, and monomeric and oligomeric states separated by filtration, and fibrillar states obtained by centrifugation after weeks of aging. Each species was validated using a combination of atomic force microscopy (AFM) and Thioflavin T (ThT) fluorescence. As expected, an increase in $\beta$ sheet and a decrease in disorder were observed during aggregation, although oligomeric $\alpha$-synuclein retained a high percentage of $\alpha$-helical structure. Interestingly, ThT fluorescence is not visible in the oligomeric and protofilament preparation, which has $\sim 54 \% \beta$-sheet as estimated by Raman spectroscopy, but a strong signal is observed in the filament preparation of which $\sim 66 \% \beta$-sheet is estimated by Raman spectroscopy. Nevertheless, this study uses high concentrations of protein $(300 \mu \mathrm{M})$, as Raman spectroscopy is not sensitive enough to detect physiological concentrations of $\alpha$-synuclein without enhancement such as in SERS. While SERS has not been applied to the detection of $\alpha$ synuclein a number of studies have applied SERS to the detection of dopamine. ${ }^{81-85}$ Dopamine decreases during PD progression with striatal dopaminergic neuronal loss reported between $30-70 \%$ before the onset of motor symptoms (for a review see ${ }^{86}$ ). This indicates that dopamine levels may be a useful biomarker for PD. Silver nanoparticles coated in the dopamine-selective compound iron nitriloacetic acid enabled the detection of dopamine in artificial cerebrospinal fluid (CSF) at femtomolar concentrations. $^{82}$ The silver nanoparticles were linked to magnetite that enabled the magnetic separation of dopaminebound nanoparticles from the remaining solution to remove the spectral contribution of other CSF components. Comparative analysis of mouse striatum using both SERS and the more conventional High Performance Liquid Chromatography-Mass Spectrometry (HPLC-MS) yielded similar dopamine concentrations ( $\sim 24 \mathrm{pmol} / \mathrm{mg}$ ), although the standard deviation of HPLC-MS measurements were $~ 5 \%$ lower. Nevertheless, the overall cost associated with each technique makes SERS favourable, with sample preparation also being faster and simpler for SERS analysis.

The assessment of patient blood samples using conventional Raman spectroscopy may also be a future direction for PD diagnosis. A study using both Raman spectroscopy and near- 
infrared spectroscopy was applied to the blood plasma of 20 individuals with clinically assessed probable PD, as well as 32 age-matched control subjects. A decrease in intensity of Raman bands corresponding to hydrocarbons $\left(\mathrm{C}-\mathrm{H} 2990 \mathrm{~cm}^{-1}\right)$, and an increase in bands corresponding to amines $\left(\mathrm{N}-\mathrm{H} 3200 \mathrm{~cm}^{-1}\right)$ and alcohols (R-OH $3330 \mathrm{~cm}^{-1}$ ) were detected in blood plasma samples of patients with PD in comparison to elderly control samples. It was hypothesised that these changes resulted from oxidative stress, as the detected functional groups exist on proteins and lipids that are sensitive to modification from an increase in reactive oxygen species, a potential biomarker for PD. ${ }^{23}$

\section{Huntington's Disease}

Huntington's disease (HD) is an autosomal dominant inherited neurodegenerative disease with an average age of onset of $\sim 40$ years and leads to cognitive, motor and psychiatric symptoms. ${ }^{87}$ $\mathrm{HD}$ is caused by a genetic mutation in the Huntington gene resulting in the expansion of a glutamine-coding region (Cytosine-Adenine-Guanine). This results in the expression of a toxic mutant Huntingtin (Htt) protein that leads to the initial degeneration of medium spiny neurons in the striatum. Genetic testing enables diagnosis, but the clinical diagnosis of onset requires the development of motor symptoms, which may occur 15 years or more after cognitive decline begins. ${ }^{88}$ Therefore, development of a predictive diagnostic tool can be beneficial and enable earlier therapeutic intervention.

The Hungtintin protein is characterised by variability in glutamine residues typically occurring as repeats in the primary sequence. $\mathrm{NMR},{ }^{89} \mathrm{CD}^{90,} 91$ and fluorescence correlation spectroscopy ${ }^{92}$ studies suggest that polyglutamine has a disordered structure, although shorter stretches of the polypeptide have been shown to adopt a PPII helical structure as shown by $\mathrm{NMR}^{93}$ and molecular dynamic simulations. ${ }^{94}$ PPII structure has also been observed by UVRRS, ${ }^{95}$ using a method developed by Mikhonin et al that correlates the frequency of the Amide III region to its dihedral $(\Psi)$ peptide bond angles. ${ }^{35}$ Furthermore, the addition of $\beta$-sheet rich polyglutamine solution led to PPII- $\beta$-sheet transition, demonstrating fibril formation through a templated misfolding mechanism. While the use of spectroscopy for characterisation has been performed for most studies up to now, imaging using Raman-based methods together with other label-free methods is desirable for visualisation and localisation studies. While this is an upcoming area of research in terms of application of Ramanbased imaging there are examples where the techniques of CARS \& SRS have been applied in neurodegenerative diseases and neurosurgical applications. ${ }^{21,}$ 22, 96-98 CARS microscopy has been used to image such polyglutamine aggregates in vivo using a $C$. elegans model. The protein was visualised by tuning to the Amide $\beta$-sheet vibration. CARS signals from YFG-tagged aggregates correlated well with fluorescence, although CARS detection was not demonstrated using a label-free protein. ${ }^{99}$

Toxicity of the mutant Htt protein has been linked to the damage of a number of sub-cellular structures commonly associated with the plasma membrane, believed to cause increased susceptibility of these cells to apoptosis. Peripheral fibroblasts have frequently been used as a potential model for HD, and it is possible that cell membrane disruption seen in this cell type could correlate with disease. This theory was tested using Raman spectroscopy in conjunction with statistical model based on Partial Least Square (PLS) analysis, to determine whether peripheral fibroblast cells provided an accurate tool for HD diagnosis. ${ }^{24}$ Fibroblasts from a 20-year-old HD sufferer, 6 years after onset, showed differences in Raman peaks at $428 \mathrm{~cm}^{-1}$ and $701 \mathrm{~cm}^{-1}$, indicative of cholesterol and cholesterol esters, in comparison to control samples. In addition, differences were seen at $1045 \mathrm{~cm}^{-1}, 1073$ $\mathrm{cm}^{-1}$ and $1130 \mathrm{~cm}^{-1}$ regions corresponding to triglycerides, phospholipids, fatty acids and proteins. Three bands were missing in the HD samples that were present in the control samples: 548 $\mathrm{cm}^{-1}, 1331 \mathrm{~cm}^{-1}$ and $1685 \mathrm{~cm}^{-1}$, which correspond to cholesterol, phospholipids and proteins. This study presents a proof of concept that identifying spectral differences between healthy and diseased subjects could produce spectral biomarkers that circumvent the need for sensitive analyte detection. A program could then be 'trained' to recognised such differences preventing the need for complex analysis, as has been demonstrated for the intraoperative detection of cancerous brain tissue with a diagnostic accuracy of $>90 \% .{ }^{100}$ Of course, this accuracy relies primarily on the number of spectra from different subjects that are used to train the program, highlighting the requirement of a large spectral database for training and standardisation of procedures for acquisition of spectra for universal applicability.

\section{Alzheimer's Disease}

Alzheimer's Disease (AD) is a progressive neurodegenerative disease characterised by widespread neuronal death leading to memory loss and cognitive decline with disease progression. Two main pathologies underlying $\mathrm{AD}$ are the aggregation of two proteins amyloid- $\beta$ (A $\beta)$ and tau into extracellular amyloid plaques and intracellular neurofibrillary tangles respectively. ${ }^{101}$

Metal ions have been associated with the aggregation and deposition of $\mathrm{A} \beta$, similarly to the prion protein (see Prion diseases section). A $\beta$ metal-coordination has also been characterised by Raman spectroscopy ${ }^{102-104}$ and indicates that $\mathrm{Zn}$ (II) may be causative of aggregation at physiological $\mathrm{pH}$, and $\mathrm{Cu}$ (II) protective. ${ }^{102}$ As with the prion protein, metal ions are coordinated by histidine $\mathrm{N}$ atoms of the imidazole ring, as seen by a shift in the histidine peak from $1570 \mathrm{~cm}^{-1}$ to $1604 \mathrm{~cm}^{-1}$ after $\mathrm{Zn}^{2+}$ induced $\mathrm{A} \beta$ aggregation ${ }^{102}$, indicative of metal binding to the histidine $\mathrm{N}_{\tau}$ atom. ${ }^{59}$ On the other hand, Fe(III) was shown to bind tyrosine phenolic oxygen groups and glutamate/aspartate carboxylate groups of $\mathrm{A} \beta \mathrm{r}^{103}$ This was shown through the resonance enhancement of metal-bound tyrosinate bands at 1604 $\mathrm{cm}^{-1}, 1504 \mathrm{~cm}^{-1}, 1278 \mathrm{~cm}^{-1}$ and $1176 \mathrm{~cm}^{-1}$. This enhancement is brought about by Raman excitation of the charge-transfer transition between phenolate and $\mathrm{Fe}(\mathrm{III})(\pi \rightarrow \mathrm{d}$, respectively) using a wavelength in the visible light region, specifically $514.5 \mathrm{~nm}$. Using the $A \beta_{1-16}$ fragment, in which there is only one tyrosine, it was demonstrated that Tyr10 in $A \beta$ is capable of coordination with $\mathrm{Fe}(\mathrm{III})$, whereas there were no changes in histidine peaks (of which the fragment has three). Alterations in the carboxylate stretch of glutamate/aspartate residues at $1402 \mathrm{~cm}^{-}$ ${ }^{1}$ also indicated that the side chains of these residues are involved in coordination with $\mathrm{Fe}(\mathrm{III})$. These observations were validated in the $A \beta_{1-40}$ peptide. Furthermore, the chelation of $\mathrm{Cu}(\mathrm{II})$ and $\mathrm{Zn}(\mathrm{II})$ ions in $A \beta$ plaques has been shown to increase bandwidth of the Amide peak in human hippocampal tissue. ${ }^{25}$ This indicates an increase in structural heterogeneity, as there is an increased contribution to the Amide band from multiple secondary structural components, further implicating metal ions in $\beta$-sheet stability and $\mathrm{A} \beta$ pathology.

Conventional Raman spectroscopy has also been used to show changes in the Amide I band of spectra from rat hippocampi after chronic ozone exposure, a potential risk factor for AD. ${ }^{105}$ An increase in $\beta$-sheet content was determined by an increase in the peak centred at $\sim 1670 \mathrm{~cm}^{-1}$ in the deconvoluted Amide I band after 60 days of ozone exposure. This correlated well with an increase in intracellular immunoreactivity for $\mathrm{A} \beta 42$. 
Resonance Raman spectroscopy, together with absorption spectroscopy, was used to demonstrate that $A \beta 40$ has cytochrome $c$ peroxidase (CCP) activity through the oxidation of CCP substrate ferrocytochrome $c$ (Cyt $c$ ) when complexed with heme(III) and in the presence of $\mathrm{H}_{2} \mathrm{O}_{2}$. Reduced Cyt $c$ characteristic Raman peaks at $1360 \mathrm{~cm}^{-1}, 1493 \mathrm{~cm}^{-1}$ and $1595 \mathrm{~cm}^{-}$
1. The addition of heme(III)-A $\beta 40$ and $\mathrm{H}_{2} \mathrm{O}_{2}$, but not heme(III)A $\beta 40$ alone, led to the oxidation of Cyt $c$ and the shift of these bands to $1373 \mathrm{~cm}^{-1}, 1503 \mathrm{~cm}^{-1}$ and $1585 \mathrm{~cm}^{-1}$ respectively. ${ }^{106}$
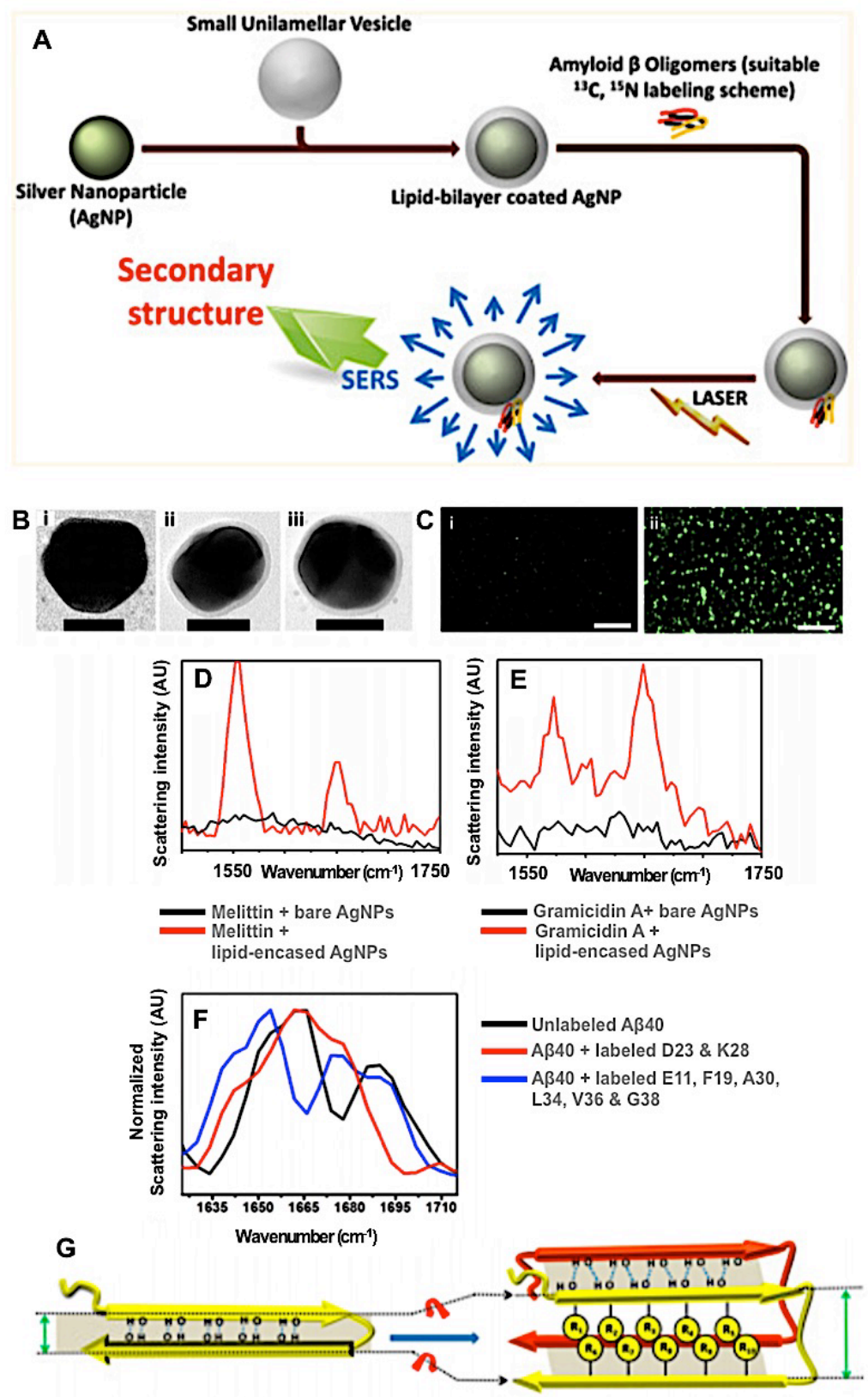

Membrane bound oligomer

Fibril

Figure 5. SERS of A $\mathbf{\beta 4 0}$ oligomers using lipid-encased Ag nanoparticles (AgNPs) (A) Schematic showing process of obtaining secondary structure information from PM-bound A $\beta 40$ oligomers using SERS and AgNPs. Small unilamellar vesicles made up of lipids POPG, POPC and cholesterol selectively bind A $\beta 40$ oligomers (B) TEM images of AgNPs (i) before coating in lipid bilayer (ii) after coating in lipid bilayer and (iii) after incubation with $2 \mu \mathrm{M}$ A $\beta 40$ oligomers. Scale bar 50nm (C) Confocal image (excitation 488nm) of (i) AgNPs (ii) AgNPs incubated with fluorescein-labelled A $\beta 40$ oligomers. Scale bar $5 \mu \mathrm{m}$ (D) SERS spectra of metallin incubated with bare AgNPs (black) and lipid-encased AgNPs (red) (E) SERS spectra of gramicidin A incubated with bare AgNPs (black) and lipid-encased AgNPs (red) (F) Amide I region of SERS spectra of unlabelled $\mathrm{A} \beta 40$ oligomers (black), ${ }^{13} \mathrm{C}$ and ${ }^{15} \mathrm{~N}$-labelled $\mathrm{A} \beta 40$ oligomers at amino acids D23 and K28 (red), ${ }^{13} \mathrm{C}$ and ${ }^{15} \mathrm{~N}$-labelled A 340 oligomers at amino acids E11, F19, A30, L34, V36 and G38 (blue) (G) Cartoon depicting change in backbone orientation from the intramolecular antiparallel $\beta$-sheet structure of membrane-bound A $\beta 40$ oligomers (which contain a $\beta$-turn) to the intermolecular parallel $\beta$-sheet structure of $\mathrm{A} \beta 40$ fibrils. Adapted from Bhowmik et al. ${ }^{107}$ 
UVRRS has been used as to study the structure of $A \beta .^{26,108,109,110}$ The flavonoid myricetin decreases the propensity for $A \beta$ to form fibrils, leading to much interest in the interactions between the flavonoid and the peptide. UVRRS revealed little measurable change in secondary structure, but a large change in aromatic amino acid environment that may be responsible for this reduced propensity. ${ }^{109,110}$ Popova et al used deuterium exchange UVRRS to probe the parallel cross- $\beta$ core of these fibrils in comparison to the antiparallel arrangement of $A \beta_{34-42}$ fibrils. A small degree of deuterium exchange for $A \beta 40$ fibrils demonstrated that most of the amino acid residues made up the parallel cross- $\beta$ core and were well protected from the solvent. In comparison, $A \beta_{34-42}$ fibrils demonstrated a large degree of deuterium exchange, as shown by the loss of intensity in Amide I and Amide III, as well as a large shift in Amide II to Amide II'. Determination the dihedral angles from the Amide III vibration (using Asher's and Mikhonin's method) ${ }^{35}$ allowed comparison of the dihedral angle distribution of the fibril core to over 1000 documented $\beta$-sheetcontaining globular proteins. ${ }^{111}$ Despite the calculated angle distributions of the $A \beta_{34-42}$ fibril core being in agreement with the average for antiparallel $\beta$-sheets in globular proteins, the dihedral angle distribution calculated for the parallel $\beta$-sheets of the $A \beta 40$ fibril core were distinctly different from the expected angle.

Further information about the structural organization of amyloid fibrils can be determined using a technique known as polarized Raman spectroscopy. ${ }^{112}$ Polarized Raman spectroscopy is a technique that probes the molecular orientation and symmetry of anisotropic molecules and can therefore be considered complimentary to XRD. Polarization sensitive detection, in two orthogonal directions, allows calculation of depolarization intensity ratios of different Raman bands to provide symmetry information as well as determination of the orientation angles of the principle axes of the Raman tensors (PARTs). These are tensors that explain the directional relationship between the polarization of the incident and Raman scattered light. ${ }^{113}$ Polarized Raman spectroscopy has been used to probe the molecular orientation of aligned insulin fibrils $^{20}$ as well as self-assembled nanotubes of diphenylalanine, a dipeptide sequence that acts as a molecular recognition motif for $\mathrm{A} \beta$ aggregation. ${ }^{114}$ In this latter work by Lekprasert et al. using intensity ratios from polarized Raman spectroscopy, it was determined that the Amide I PART is oriented parallel to the axis with a calculated angle of $41 \pm 4^{\circ}$, and the Amide III PART is oriented perpendicular to the tube axis with calculated angle of $59 \pm 5^{\circ}$; this would correspond to the carbonyl $\mathrm{C}=\mathrm{O}$ bond orientation angle of $8 \pm 4^{\circ}$ from the nanotube axis. This information enabled a structural model of the nanotube to be created that aligned well with $\mathrm{X}$ ray data from crystals.

In order to study the monomeric structure of $A \beta$ and the early stages of aggregation more closely, Bhowmik et al prevented aggregation using an $\mathrm{A} \beta 40$ monomer with a $\mathrm{C}$-terminal cysteine residue bound directly to silver nanoparticles for surface enhancement. ${ }^{115}$ No shift in the Amide I band was reported in aggregate-prone $\mathrm{pH}$, indicating that intermolecular association of monomers may precede conformational change in $\mathrm{pH}$ dependent aggregation. The fibrillization of $\mathrm{A} \beta 42$ has been assessed using silver nanoparticles coated in a $5 \mathrm{~nm}$ silica shell that prevents amine-silver bond formation. ${ }^{30}$ A shift in the Amide III band over $120 \mathrm{~h}$ of peptide incubation demonstrated an $\alpha$-helical to $\beta$-sheet transition, although there was no proof provided that indeed the 0 h A $\beta$ sample consisted of a homogenous monomer. Similar results have been obtained using microfluidic devices that trap $A \beta$ in a microchannel with SERS active nanoparticles. This increases the local concentration of the protein enabling physiologically relevant concentrations of $A \beta$ to be detected. ${ }^{27,116}$ The conversion from $\alpha$-helical to a $\beta$-sheet structure in $A \beta 40$ was reported using
SERS, as a function of time ${ }^{27}$ and at concentrations as low as 10 $\mathrm{fM}{ }^{116}$ however, complementary CD analysis was not able to distinguish between secondary structures at $100 \mathrm{pM}$ and less concentrations. Such microfluidic devices have not been applied to complex mixture analysis for diagnostic applications, with congestion from other blood/CSF components and $\mathrm{A} \beta$ binding selectivity as the likely technical issues that will need to be addressed.

A SERS method using silver nanoparticles coated in a lipid bilayer that mimics that of a cell was used to probe the structure of $\mathrm{A} \beta$ oligomers that spontaneously bind to cellular plasma membranes (PMs) (figure 5). ${ }^{107}$ The affinity of small oligomers towards the PM may be central in neurotoxicity through the formation of ion channels that disrupt homeostasis. ${ }^{117}$ Further evidence for this hypothesis was provided by SERS analysis coupled with isotopic substitutions that enables the localisation of secondary structural components within a molecule based on frequency shifts observed in the resulting Raman spectrum. Bhowmilk et al revealed a $\beta$-turn structural component between residues 23-28 flanked by antiparallel $\beta$-sheets for PM-bound A $\beta 40$ oligomers, which is a conformational characteristic shared by porins.

Spectral biomarkers that correlate to the development of AD have been examined using conventional Raman Spectroscopy. This was initially demonstrated in post-mortem human brain tissue, ${ }^{118}$ and in the hippocampus of a rat model of AD, which both showed an expected increase in $\beta$-sheet content. ${ }^{119}$ Mass spectrometry analysis of human eye lenses indicated that $A \beta$ is present in cataracts of post-mortem $\mathrm{AD}$ patients, and $\mathrm{A} \beta$ may promote lens protein aggregation. ${ }^{120}$ However, spectral differences between protein aggregates of the hippocampus and cortical cataracts of eye lenses using Raman spectroscopy, ${ }^{121}$ together with the lack of A $\beta$ immunostaining in the lens, ${ }^{122}$ suggests that cortical cataracts may not be a reliable $\mathrm{AD}$ biomarker. $\mathrm{AD}$ blood samples have also been assessed for spectral biomarkers, with the most significant spectral differences relating to changes in platelets. This is understandable, as there are a number of biochemical alterations to platelets related to $\mathrm{AD},{ }^{123}$ including changes in Amyloid Precursor Protein (APP) processing. ${ }^{124,125}$ Platelets from mice, ${ }^{126}$ and rat $^{28}$ models of $\mathrm{AD}$ suggest that platelets can be used to distinguish between control and AD rodent models with over $90 \%$ accuracy, as well as between $\mathrm{AD}$ and $\mathrm{PD}$ and vascular dementia. ${ }^{126}$ Carmona et al demonstrated that an increase in the ratio between spectral bands at $758 \mathrm{~cm}^{-1}$ and $744 \mathrm{~cm}^{-1}$ is observed in the blood plasma of patients with both mild and severe $A D$, where $758 \mathrm{~cm}^{-1}$ corresponds to the Tryptophan side chain indolering breathing mode and the pyrrole/heme-sensitive band at 744 $\mathrm{cm}^{-1}$ likely corresponds to mitochondrial cytochrome $\mathrm{C}$ from platelets..$^{29,127}$ Area under the curve (AUC) analysis (a measure of diagnostic test accuracy ${ }^{128}$ ) suggested that this intensity ratio alone should be able to distinguish between healthy controls and AD patients with $87 \%$ accuracy, and combining spectral biomarkers from both Raman and IR spectroscopies produced an AUC value of 0.94 . However, this accuracy may decrease when applied to large heterogenous populations, especially when comparing with other dementias that may produce similar spectral biomarkers. That being said, Ryzhikova et al showed that spectral differences identified by PCA and significant factor analysis could be used to specify AD from other types of dementia with a predicted accuracy of 95\%, although sample sizes were small. ${ }^{129}$ Nevertheless, these studies demonstrate the potential of Raman spectroscopy as a diagnostic probe using patient biofluids.

Conventional Raman spectroscopy together with multivariate statistical analysis can be used to detect spectral biomarkers that 
are applicable to disease diagnosis, but this method alone is not sensitive enough for analyte detection. A number of different SERS technologies have been developed to overcome the limitation of conventional Raman spectroscopy in the detection of $\mathrm{A} \beta$ and tau at physiological concentrations. Firstly, there are indirect methods of detection that measure structural changes in a substrate that is selective to $A \beta$. For example, Raman spectra of the $\beta$-sheet dye Congo red have been used as quantitative readouts of $A \beta$ concentration after binding to sialic acid coated nanoshells. ${ }^{130,} 131 \mathrm{~A} \beta$ detection has also been addressed by measuring changes in positively charged compounds such as N(6-mercapto)hexylpyridinium (MHP) chloride and alkanethiols. Such compounds have the advantage of forming self-assembled monolayers (SAM) on metal surfaces and enable hydrophobic interactions to be studied. Spectral differences were observed for small and large $A \beta$ oligomers using both MHP and heptanethiol monolayers, which may enable toxic species to be distinguished. ${ }^{132}$ Finally, changes in $\mathrm{Al}^{3+}$ coordination by MBAcoated gold-decorated polystyrene beads have also been assessed after the addition of amyloid-like model oligomers consisting of Escherichia coli protein HypF-N. ${ }^{133}$ SERS sensors have also been developed for the detection of the neurotransmitter $\gamma$ aminobutyric acid (GABA). ${ }^{134-137}$ Reductions in the levels of GABA have been observed in the CSF of $A D, P D$ and $H D$ patients. ${ }^{138}$ Despite not being a disease-specific biomarker, GABA levels may be useful for neurodegenerative disease screening and determining the risk of onset. Monfared et al used a combination of Glutamate and GABA preparations in serum that were combined with colloidal silver nanoparticles for surface enhancement. PLS was then used for quantification, as the first two principle components for the spectra of different ratios of neurotransmitter clustered based on concentration. ${ }^{135}$ The direct measurement of $A \beta$ using SERS has been achieved by drying $A \beta 40$ oligomers onto the surface of a gold-coated, ripplemodified sapphire substrate, ${ }^{139}$ but such methods have not been applied to complex mixtures. Antibody-coated nanoparticles that allow the direct detection of $\mathrm{A} \beta,{ }^{140}$ tau, ${ }^{141}$ or both ${ }^{142}$ in complex mixtures have been employed that pose a number of advantages over current ELISA methods. Fingerprinting via Raman spectroscopy increases the reliability and specificity of results that are fully quantitative in comparison to visualization using secondary antibodies. This also makes analysis more rapid than for most commercially available ELISA kits, and signal enhancement results in a far superior limit of detection, which was reported as low as $100 \mathrm{fg} / \mathrm{ml}$ for tau. ${ }^{142}$ Nevertheless, these methods do not circumvent the limitations of using antibodies that are biased towards a specific epitope that may be occluded on different species of $A \beta$ or Tau. A reagent-minimizing method is preferable and attaining similar levels of detection in complex mixtures without the use of antibodies may be possible using multivariate statistical analysis.

There are a number of lipidomic changes associated with $\mathrm{AD}$ and alterations in lipid compositions may contribute to the development of the disease. ${ }^{143}$ CARS imaging has been used to visualize amyloid plaque-associated lipids in human $A D$ prefrontal cortex samples (Figure 6). ${ }^{22}$ A tuneable pump beam was used between 807-825 $\mathrm{nm}$ alongside a fixed Stokes beam frequency of $1064 \mathrm{~nm}$ in order to visualise lipid specific C-H vibrations. Lipid fluidity was calculated by the CARS intensity ratio of symmetric $\left(2840 \mathrm{~cm}^{-1}\right)$ to asymmetric $\left(2870 \mathrm{~cm}^{-1}\right)$ stretching vibrations and was shown to be variable throughout the plaque region. Lipids were initially colocalised to plaques using thioflavin S staining. Lipid aggregates in unstained samples were shown to colocalise with plaques using Raman microspectroscopy, due to the presence of $\beta$-sheet $\left(1667 \mathrm{~cm}^{-1}\right)$ in the location of, but not surrounding, lipid aggregates. It has been demonstrated that natural lipids contribute to the fragmentation and solubilization of mature $\mathrm{A} \beta$ fibrils and produce toxic 'backward' protofibrils. ${ }^{144}$ Therefore, plaque regions with increased fluidity may have a higher rate of $A \beta$ fibril fragmentation that may impact the number of toxic $A \beta$ oligomers that are released from amyloid plaques.

\section{CARS Images \& Spectra}
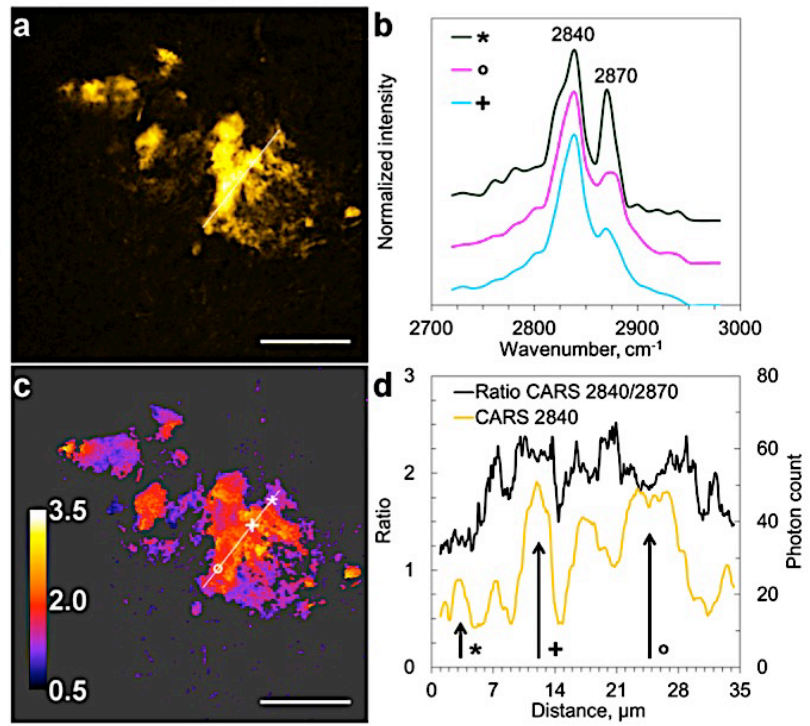

Raman Spectra
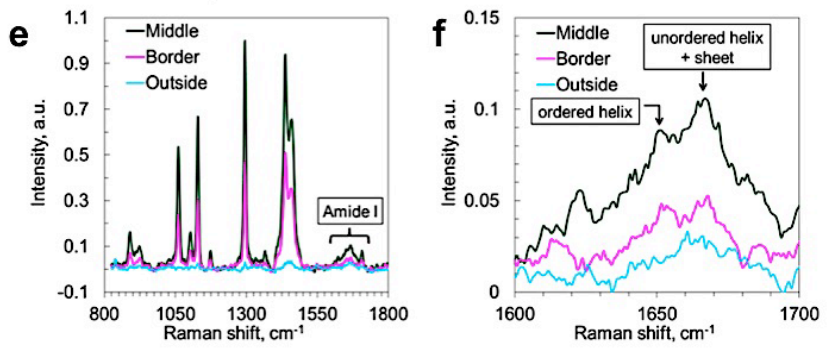

Figure 6. CARS images of lipid aggregates correlate with $\beta$ sheet (a) CARS image of lipid aggregate at $2840 \mathrm{~cm}^{-1}$ (b) CARS spectra collected at positions identified by corresponding symbols in c (c) Lipid fluidity demonstrated by variations in CARS ratio intensities 2840:2870 $\mathrm{cm}^{-1}$ (d) Profile plots along lines in $\mathrm{A} / \mathrm{C}$ that contain corresponding symbols. Scale bars $=25$ um. (e) Raman spectra corresponding to the middle, border and outside of lipid aggregates (f) Zoomed in Amide I band of a indicates a higher level of $\beta$-sheet localised to lipid aggregates as opposed to surrounding tissue. Adapted from Kiskis et al. ${ }^{22}$

Lee et al have recently developed a multimodal, multiphoton microscopy system enabling simultaneous CARS, Second Harmonic Generation and two-photon excited fluorescence imaging. ${ }^{21}$ CARS images of hippocampal sections from 29 weekold 5x FAD mice (mouse model with severe amyloid pathology due to 3 mutations in the APP gene and 2 mutations in the $\gamma$ secretase subunit presenilin-1/PSEN1 gene) and age-matched controls were acquired using the symmetric C-H stretching vibrational mode of lipids. Increased lipid intensities were observed in 5x FAD mice that may serve as a disease biomarker, with a $4 \mathrm{x}$ increase in the ratio of lipid $\mathrm{CH}_{2}: \mathrm{CH}_{3}$ stretching vibrations (I2845:I2930). The group are working to develop this system into a diagnostic tool using optical fiber bundles to enable 
in vivo imaging, although this would require a more invasive procedure than the assessment of biofluids.

Although relatively less studied by Raman spectroscopy, Tau is recognized as the second major contributor to $\mathrm{AD}$ pathology. Both loss of physiological microtubule binding function, ${ }^{145}$ and gain of toxic function as a result of aggregation have been proposed. ${ }^{146,} 147$ In a normal system, tau protein binds to microtubules (MTs) to stabilize them within neurons and hence allowing effective transport within these cells. In $\mathrm{AD}$ this protein becomes abnormally phosphorylated, and detaches from the MTs and aggregates to form oligomers and tangles. ${ }^{148}$ ROA studies using human recombinant tau 46 (human brain tau of 412 amino acids) and the tau 46 p301 mutant that is associated with frontotemporal dementia, have confirmed that the protein has a PPII structure due to the presence of the characteristic strong positive band $\sim 1316 \mathrm{~cm}^{-1}-1318 \mathrm{~cm}^{-1}$ in the ROA spectrum. ${ }^{75}$ The kinetics of heparin-induced tau fibrillation has been assessed using UVRSS in combination with ThT fluorescence, AFM and sedimentation assays. ${ }^{149}$ A rapid transition from disordered monomer to a $\beta$-sheet rich fibril was observed by downshifts in both Amide I $\left(1681 \mathrm{~cm}^{-1} \rightarrow 1675 \mathrm{~cm}^{-1}\right)$ and Amide III $\left(1238 \mathrm{~cm}^{-1}\right.$ $\rightarrow 1229 \mathrm{~cm}^{-1}$ ) that correlated with the sedimentation of $\sim 90 \%$ of the tau protein and the formation of small clumps of ordered fibrils as observed by AFM.

\section{Conclusions \& Future Perspectives}

The aim of this review was to highlight the potential of Raman scattering based techniques in the analysis of protein structure and the diagnosis of neurodegenerative diseases. An emerging concept in the field of neurodegenerative disease is that the different pathologies observed in different diseases may be caused by different strains of aggregated protein. ${ }^{147,150-156}$ For example, there are several tauopathies (diseases in which there is a pathological aggregation of tau protein) that may be a result of, or lead to the production of, different molecular conformations of tau. Such 'conformers' are reminiscent of prion strains and suggest a precise structure-toxicity relationship. Polarized Raman is well-suited to probing differences in the molecular orientation of fibrillar conformers, whilst the structural diversity of the cross$\beta$-core of morphologically distinct prion fibrils has been assessed using DUVRR by Shashilov et al, as discussed previously (figure 3). Characterization of tau strains from different tauopathies using such methods may reveal details about this structure-toxicity relationship and provide evidence for the protein strain hypothesis, whilst also providing potential diagnostic fingerprints and drug targets. As well as a conformational readout, Raman spectroscopy can also provide information about the posttranslational modification of proteins, many of which have been characterized by Raman spectroscopy, including phosphorylation, ${ }^{157}, 158$ which is particularly relevant to tau and $\mathrm{AD}$.

Further characterization of structural changes in toxic proteins in vitro is also essential for diagnostic applications; as such fingerprints may themselves be effective biomarkers. For future translation into a clinical setting it is also necessary to establish a database or 'spectral library' consisting of all recorded spectra from both patient and control samples, as well as protein fingerprints, which can be used together for reliable automated screening of unknown samples. Despite clear benefits including rapid label-free fingerprinting and limited sample preparation, diagnostic tools using Raman spectroscopy are underdeveloped and examples of spectral biomarkers in patient biofluids are limited. The reproducibility of such biomarkers needs to be demonstrated in large heterogeneous cohorts and must be able to reliably distinguish between different neurodegenerative and psychiatric disorders. This has recently been demonstrated using attenuated internal reflection FTIR to assess the fingerprint region of blood samples by Paraskevaidi et al. Spectroscopic information in combination with apolipoprotein $\varepsilon 4$ (APOE) genotype was shown to improve diagnostic performance for AD in comparison to spectroscopy alone. ${ }^{159}$ Carmona et al showed an improved diagnostic performance when using both Raman spectroscopy and IR spectroscopy in combination, ${ }^{29}$ as described earlier, suggesting that the use of such complimentary techniques may be necessary for an accurate neurodegenerative disease diagnosis.

Spontaneous Raman spectroscopy lends itself well to the measurement of unprocessed bulk samples, from which classification can be achieved using multivariate statistical methods. Further sample processing or enrichment may be necessary when looking at alterations in a specific molecule or biomarker, due to the low signal from Raman scattered light and interference from other molecules within the sample that contain similar functional groups/chemical bonding. The low sensitivity of Raman spectroscopy has been addressed using SERS and coherent Raman approaches, with respective advances in nanoparticle development and in vivo imaging systems. However, the application of these technologies to clinical samples, or even cell-based systems and animal models, is a research frontier only beginning to be addressed. As well as the diagnosis of human disease, the work from Carmona et $a l^{67}$ has indicated that rapid livestock screening for $\mathrm{PrP}^{\mathrm{Sc}}$ using Raman spectroscopy would benefit both agricultural economy and public health. Yet a final consideration will be the cost associated with Raman spectroscopy as a diagnostic/screening tool. Although minimizing reagents reduces the cost of upkeep, the upfront cost of the system (including laser, spectrometer, microscope/endoscope) can be expensive. While small, portable and relatively inexpensive Raman spectrometers are available their suitability (sensitivity) for clinical use has not yet been established. For imaging applications entry-level costs are indeed prohibitive and again development of low-cost lasers is an area of intense research and development. Recent progress with use of Raman spectroscopy for intraoperative brain cancer detection is highly promising. ${ }^{100}$ Selective sampling methodologies, such as those demonstrated by Kong et $a l,{ }^{51}$ may shed light on chemical changes in the microenvironment of cells during the aggregation and spreading of misfolded proteins. Nevertheless, despite there being some work required before Raman spectroscopy and Raman imaging techniques are readily available and widely deployed in the clinic, there is no doubt that with significant development the power and simplicity of this technique has the potential to revolutionize neurodegenerative disease screening and diagnosis in the future.

\section{REFERENCES}

[1] Hebert, L. E., Weuve, J., Scherr, P. A., and Evans, D. A. (2013) Alzheimer disease in the United States (20102050) estimated using the 2010 census, Neurology 80, 1778-1783.

[2] von Campenhausen, S., Bornschein, B., Wick, R., Botzel, K., Sampaio, C., Poewe, W., Oertel, W., Siebert, U., Berger, K., and Dodel, R. (2005) Prevalence and incidence of Parkinson's disease in Europe, European Neuropsychopharmacology 15, 473-490.

[3] Humpel, C. (2011) Identifying and validating biomarkers for Alzheimer's disease, Trends in Biotechnology 29, 26-32.

[4] Skovronsky, D. M., Lee, V. M. Y., and Trojanowskiz, J. Q. (2006) Neurodegenerative diseases: New concepts of pathogenesis and their therapeutic implications, Annual 
Review of Pathology-Mechanisms of Disease 1, 151170.

[5] Pelton, J. T., and McLean, L. R. (2000) Spectroscopic methods for analysis of protein secondary structure, Analytical Biochemistry 277, 167-176.

[6] Uversky, V. N. (2015) Intrinsically disordered proteins and their (disordered) proteomes in neurodegenerative disorders, Frontiers in Aging Neuroscience 7.

[7] Braak, H., and Braak, E. (1991) Neuropathological staging of Alzheimer-related changes, Acta Neuropathologica 82, 239-259.

[8] Galasko, D., Klauber, M. R., Hofstetter, C. R., Salmon, D. P., Lasker, B., and Thal, L. J. (1990) The mini-mental state examination in the early diagnosis of Alzheimersdisease, Archives of Neurology 47, 49-52.

[9] Wollman, D. E., and Prohovnik, I. (2003) Sensitivity and specificity of neuroimaging for the diagnosis of Alzheimer's disease, Dialogues in clinical neuroscience 5, 89-99.

[10] Marcus, C., Mena, E., and Subramaniam, R. M. (2014) Brain PET in the Diagnosis of Alzheimer's Disease, Clinical Nuclear Medicine 39, E413-E426.

[11] Tighe, P. J., Ryder, R. R., Todd, I., and Fairclough, L. C. (2015) ELISA in the multiplex era: Potentials and pitfalls, Proteomics Clinical Applications 9, 406-422.

[12] Downes, A., and Elfick, A. (2010) Raman Spectroscopy and Related Techniques in Biomedicine, Sensors 10, 18711889.

[13] Koenig, J. L. (1972) Raman spectroscopy of biological molecules: a review, Journal of Polymer Science, Macromolecular Reviews 6, 59-177.

[14] Ellis, D. I., Cowcher, D. P., Ashton, L., O'Hagan, S., and Goodacre, R. (2013) Illuminating disease and enlightening biomedicine: Raman spectroscopy as a diagnostic tool, Analyst 138, 3871-3884.

[15] Austin, L. A., Osseiran, S., and Evans, C. L. (2016) Raman technologies in cancer diagnostics, Analyst 141, 476503.

[16] Shipp, D. W., Sinjab, F., and Notingher, I. (2017) Raman spectroscopy: techniques and applications in the life sciences, Advances in Optics and Photonics 9, 315-428.

[17] Fan, M. K., Andrade, G. F. S., and Brolo, A. G. (2011) A review on the fabrication of substrates for surface enhanced Raman spectroscopy and their applications in analytical chemistry, Analytica Chimica Acta 693, 7-25.

[18] Tolles, W. M., Nibler, J. W., McDonald, J. R., and Harvey, A. B. (1977) Review of theory and application of coherent anti-Stokes Raman-spectroscopy (CARS), Applied Spectroscopy 31, 253-271.

[19] Raman, C. V., and Krishnan, K. S. (1998) A new type of secondary radiation (Reprinted from Nature, vol 121, pg 501-502, 1928), Current Science 74, 381-381.

[20] Sereda, V., Sawaya, M. R., and Lednev, I. K. (2015) Structural Organization of Insulin Fibrils Based on Polarized Raman Spectroscopy: Evaluation of Existing Models, Journal of the American Chemical Society 137, 11312-11320.

[21] Jang Hyuk, L., Dae Hwan, K., Woo Keun, K., Myoung-Kyu, O., and Do-Kyeong, K. (2015) Label-free imaging and quantitative chemical analysis of Alzheimer's disease brain samples with multimodal multiphoton nonlinear optical microspectroscopy, Journal of Biomedical Optics 20, 056013 (056017 pp.)-056013 (056017 pp.).

[22] Kiskis, J., Fink, H., Nyberg, L., Thyr, J., Li, J.-Y., and Enejder, A. (2015) Plaque-associated lipids in Alzheimer's diseased brain tissue visualized by nonlinear microscopy, Scientific Reports 5.
[23] Schipper, H. M., Kwok, C. S., Rosendahl, S. M., Bandilla, D., Maes, O., Melmed, C., Rabinovitch, D., and Burns, D. H. (2008) Spectroscopy of human plasma for diagnosis of idiopathic Parkinson's disease, Biomarkers in Medicine 2, 229-238.

[24] Muratore, M. (2013) Raman spectroscopy and partial least squares analysis in discrimination of peripheral cells affected by Huntington's disease, Analytica Chimica Acta 793, 1-10.

[25] Dong, J., Atwood, C. S., Anderson, V. E., Siedlak, S. L., Smith, M. A., Perry, G., and Carey, P. R. (2003) Metal binding and oxidation of amyloid-beta within isolated senile plaque cores: Raman microscopic evidence, Biochemistry 42, 2768-2773.

[26] Ramachandran, G., Milan-Garces, E. A., Udgaonkar, J. B., and Puranik, M. (2014) Resonance Raman Spectroscopic Measurements Delineate the Structural Changes that Occur during Tau Fibril Formation, Biochemistry 53, 6550-6565.

[27] Chou, I. H., Benford, M., Beier, H. T., Cote, G. L., Wang, M., Jing, N., Kameoka, J., and Good, T. A. (2008) Nanofluidic biosensing for beta-amyloid detection using surface enhanced Raman spectroscopy, Nano Letters 8, 1729-1735.

[28] Park, A., Baek, S.-J., Shen, A., and Hu, J. (2013) Detection of Alzheimer's disease by Raman spectra of rat's platelet with a simple feature selection, Chemometrics and Intelligent Laboratory Systems 121, 52-56.

[29] Carmona, P., Molina, M., Lopez-Tobar, E., and Toledano, A. (2015) Vibrational spectroscopic analysis of peripheral blood plasma of patients with Alzheimer's disease, Analytical and Bioanalytical Chemistry 407, 77477756.

[30] Wang, Q., Wang, Y., and Lu, H. P. (2013) Revealing the secondary structural changes of amyloid beta peptide by probing the spectral fingerprint characters, Journal of Raman Spectroscopy 44, 670-674.

[31] Maiti, N. C., Apetri, M. M., Zagorski, M. G., Carey, P. R., and Anderson, V. E. (2004) Raman spectroscopic characterization of secondary structure in natively unfolded proteins: alpha-synuclein, Journal of the American Chemical Society 126, 2399-2408.

[32] Rygula, A., Majzner, K., Marzec, K. M., Kaczor, A., Pilarczyk, M., and Baranska, M. (2013) Raman spectroscopy of proteins: a review, Journal of Raman Spectroscopy 44, 1061-1076.

[33] Miura, T., Horii, A., and Takeuchi, H. (1996) Metaldependent alpha-helix formation promoted by the glycine-rich octapeptide region of prion protein, Febs Letters 396, 248-252.

[34] Cowan, C. M., Quraishe, S., Hands, S., Sealey, M., Mahajan, S., Allan, D. W., and Mudher, A. (2015) Rescue from tau-induced neuronal dysfunction produces insoluble tau oligomers, Scientific Reports 5.

[35] Mikhonin, A. V., Bykov, S. V., Myshakina, N. S., and Asher, S. A. (2006) Peptide secondary structure folding reaction coordinate: Correlation between UV Raman amide III frequency, Psi Ramachandran angle, and hydrogen bonding, Journal of Physical Chemistry $B$ 110, 1928-1943.

[36] Mikhonin, A. V., Myshakina, N. S., Bykov, S. V., and Asher, S. A. (2005) UV resonance Raman determination of polyproline II, extended 2.5(1)-helix, and beta-sheet psi angle energy landscape in poly-L-lysine and poly-Lglutamic acid, Journal of the American Chemical Society $127,7712-7720$. 
[37] Yamamoto, K., Sakamoto, A., Nagano, T., and Fukumitsu, K. (2010) NIR sensitivity enhancement by laser treatment for Si detectors, Nuclear Instruments \& Methods in Physics Research Section a-Accelerators Spectrometers Detectors and Associated Equipment 624, 520-523.

[38] Spiro, T. G., and Strekas, T. C. (1974) Resonance Ramanspectra of heme proteins - effects of oxidation and spin state, Journal of the American Chemical Society 96, 338-345.

[39] Ozdemir, A., Lednev, I. K., and Asher, S. A. (2002) Comparison between UV Raman and circular dichroism detection of short alpha helices in Bombolitin III, Biochemistry 41, 1893-1896.

[40] Asher, S. A., Ianoul, A., Mix, G., Boyden, M. N., Karnoup, A., Diem, M., and Schweitzer-Stenner, R. (2001) Dihedral psi angle dependence of the amide III vibration: A uniquely sensitive UV resonance Raman secondary structural probe, Journal of the American Chemical Society 123, 11775-11781.

[41] Song, S. H., and Asher, S. A. (1989) UV Resonance Raman studies of peptide conformation in poly(l-lysine), poly(lglutamic acid), and model complexes - the basis for protein secondary structure determinations, Journal of the American Chemical Society 111, 4295-4305.

[42] Chi, Z. H., Chen, X. G., Holtz, J. S. W., and Asher, S. A. (1998) UV resonance Raman-selective amide vibrational enhancement: Quantitative methodology for determining protein secondary structure, Biochemistry 37, 2854-2864.

[43] Trevisan, J., Angelov, P. P., Carmichael, P. L., Scott, A. D., and Martin, F. L. (2012) Extracting biological information with computational analysis of Fouriertransform infrared (FTIR) biospectroscopy datasets: current practices to future perspectives, Analyst 137, 3202-3215.

[44] Gautam, R., Vanga, S., Ariese, F., and Umapathy, S. (2015) Review of multidimensional data processing approaches for Raman and infrared spectroscopy, Epj Techniques and Instrumentation 2.

[45] Taketani, A., Hariyani, R., Ishigaki, M., Andriana, B. B., and Sato, H. (2013) Raman endoscopy for the in situ investigation of advancing colorectal tumors in live model mice, Analyst 138, 4183-4190.

[46] Kneipp, K., Kneipp, H., Itzkan, I., Dasari, R. R., and Feld, M. S. (1999) Ultrasensitive chemical analysis by Raman spectroscopy, Chemical reviews 99, 2957-2976.

[47] Shashilov, V., Xu, M., Makarava, N., Savtchenko, R., Baskakov, I. V., and Lednev, I. K. (2012) Dissecting Structure of Prion Amyloid Fibrils by HydrogenDeuterium Exchange Ultraviolet Raman Spectroscopy, Journal of Physical Chemistry B 116, 7926-7930.

[48] Camp, C. H., Lee, Y. J., Heddleston, J. M., Hartshorn, C. M., Walker, A. R. H., Rich, J. N., Lathia, J. D., and Cicerone, M. T. (2014) High-speed coherent Raman fingerprint imaging of biological tissues, Nature Photonics 8, 627-634.

[49] Min, W., Freudiger, C. W., Lu, S. J., and Xie, X. S. (2011) Coherent Nonlinear Optical Imaging: Beyond Fluorescence Microscopy, Annual Review of Physical Chemistry, Vol 62 62, 507-530.

[50] Tipping, W. J., Lee, M., Serrels, A., Brunton, V. G., and Hulme, A. N. (2016) Stimulated Raman scattering microscopy: an emerging tool for drug discovery, Chemical Society Reviews 45, 2075-2089.

[51] Kong, K., Rowlands, C. J., Elsheikha, H., and Notingher, I. (2012) Label-free molecular analysis of live Neospora caninum tachyzoites in host cells by selective scanning Raman micro-spectroscopy, Analyst 137, 4119-4122.

[52] Caine, D., Tinelli, R. J., Hyare, H., De Vita, E., Lowe, J., Lukic, A., Thompson, A., Porter, M.-C., Cipolotti, L., Rudge, P., Collinge, J., and Mead, S. (2015) The cognitive profile of prion disease: a prospective clinical and imaging study, Annals of Clinical and Translational Neurology 2, 548-558.

[53] Pan, K. M., Baldwin, M., Nguyen, J., Gasset, M., Serban, A., Groth, D., Mehlhorn, I., Huang, Z. W., Fletterick, R. J., Cohen, F. E., and Prusiner, S. B. (1993) Conversion of alpha-helices into beta-sheets features in the formation of the scrapie prion proteins, Proceedings of the National Academy of Sciences of the United States of America 90, 10962-10966.

[54] Barron, L. D., and Buckingh.Ad. (1971) Rayleigh and Raman scattering from optically active molecules, Molecular Physics 20, 1111-\&amp;

[55] Tam, C. N., Bour, P., and Keiderling, T. A. (1997) An experimental comparison of vibrational circular dichroism and Raman optical activity with 1-amino-2propanol and 2-amino-1-propanol as model compounds, Journal of the American Chemical Society 119, 70617064.

[56] McColl, I. H., Blanch, E. W., Gill, A. C., Rhie, A. G. O., Ritchie, M. A., Hecht, L., Nielsen, K., and Barron, L. D. (2003) A new perspective on beta-sheet structures using vibrational Raman optical activity: From poly(L-lysine) to the prion protein, Journal of the American Chemical Society 125, 10019-10026.

[57] Donne, D. G., Viles, J. H., Groth, D., Mehlhorn, I., James, T. L., Cohen, F. E., Prusiner, S. B., Wright, P. E., and Dyson, H. J. (1997) Structure of the recombinant fulllength hamster prion protein $\operatorname{PrP}(29-231)$ : The $\mathrm{N}$ terminus is highly flexible, Proceedings of the National Academy of Sciences of the United States of America 94, 13452-13457.

[58] Hornshaw, M. P., McDermott, J. R., and Candy, J. M. (1995) Copper-binding to the $\mathrm{N}$-terminal tandem repeat regions of mammalian and avian prion protein, Biochemical and Biophysical Research Communications 207, 621-629.

[59] Miura, T., Hori-i, A., Mototani, H., and Takeuchi, H. (1999) Raman spectroscopic study on the copper(II) binding mode of prion octapeptide and its $\mathrm{pH}$ dependence, Biochemistry 38, 11560-11569.

[60] Miura, T., Sasaki, S., Toyama, A., and Takeuchi, H. (2005) Copper reduction by the octapeptide repeat region of prion protein: $\mathrm{pH}$ dependence and implications in cellular copper uptake, Biochemistry 44, 8712-8720.

[61] Thackray, A. M., Knight, R., Haswell, S. J., Bujdoso, R., and Brown, D. R. (2002) Metal imbalance and compromised antioxidant function are early changes in prion disease, Biochemical Journal 362, 253-258.

[62] Zhu, F., Davies, P., Thompsett, A. R., Kelly, S. M., Tranter, G. E., Hecht, L., Isaacs, N. W., Brown, D. R., and Barron, L. D. (2008) Raman optical activity and circular dichroism reveal dramatic differences in the influence of divalent copper and manganese ions on prion protein folding, Biochemistry 47, 2510-2517.

[63] Manno, D., Filippo, E., Fiore, R., Serra, A., Urso, E., Rizzello, A., and Maffia, M. (2010) Monitoring prion protein expression in complex biological samples by SERS for diagnostic applications, Nanotechnology 21.

[64] Serra, A., Manno, D., Filippo, E., Buccolieri, A., Urso, E., Rizzello, A., and Maffia, M. (2011) SERS based optical sensor to detect prion protein in neurodegenerate living cells, Sensors and Actuators B-Chemical 156, 479-485. 
[65] Croes, E. A., Theuns, J., Houwing-Duistermaat, J. J., Dermaut, B., Sleegers, K., Roks, G., Van den Broeck, M., van Harten, B., van Swieten, J. C., Cruts, M., Van Broeckhoven, C., and van Duijn, C. M. (2004) Octapeptide repeat insertions in the prion protein gene and early onset dementia, Journal of Neurology Neurosurgery and Psychiatry 75, 1166-1170.

[66] Stevens, D. J., Walter, E. D., Rodriguez, A., Draper, D., Davies, P., Brown, D. R., and Millhauser, G. L. (2009) Early Onset Prion Disease from Octarepeat Expansion Correlates with Copper Binding Properties, Plos Pathogens 5.

[67] Carmona, P., Monleon, E., Monzon, M., Badiola, J. J., and Monreal, J. (2004) Raman analysis of priori protein in blood cell membranes from naturally affected scrapie sheep, Chemistry \&amp; Biology 11, 759-764.

[68] Solari, N., Bonito-Oliva, A., Fisone, G., and Brambilla, R. (2013) Understanding cognitive deficits in Parkinson's disease: lessons from preclinical animal models, Learning \&amp; Memory 20, 592-600.

[69] Spillantini, M. G., Schmidt, M. L., Lee, V. M. Y., Trojanowski, J. Q., Jakes, R., and Goedert, M. (1997) alpha-synuclein in Lewy bodies, Nature 388, 839-840.

[70] Martin, F. L., Williamson, S. J. M., Paleologou, K. E., Allsop, D., and El-Agnaf, O. M. A. (2004) alphasynuclein and the pathogenesis of Parkinson's disease, Protein and Peptide Letters 11, 229-237.

[71] Weinreb, P. H., Zhen, W. G., Poon, A. W., Conway, K. A., and Lansbury, P. T. (1996) NACP, a protein implicated in Alzheimer's disease and learning, is natively unfolded, Biochemistry 35, 13709-13715.

[72] Conway, K. A., Harper, J. D., and Lansbury, P. T. (1998) Accelerated in vitro fibril formation by a mutant alphasynuclein linked to early-onset Parkinson disease, Nature Medicine 4, 1318-1320.

[73] Fauvet, B., Mbefo, M. K., Fares, M. B., Desobry, C., Michael, S., Ardah, M. T., Tsika, E., Coune, P., Prudent, M., Lion, N., Eliezer, D., Moore, D. J., Schneider, B., Aebischer, P., El-Agnaf, O. M., Masliah, E., and Lashuel, H. A. (2012) alpha-Synuclein in Central Nervous System and from Erythrocytes, Mammalian Cells, and Escherichia coli Exists Predominantly as Disordered Monomer, Journal of Biological Chemistry 287, 15345-15364.

[74] Eliezer, D., Kutluay, E., Bussell, R., and Browne, G. (2001) Conformational properties of alpha-synuclein in its free and lipid-associated states, Journal of Molecular Biology 307, 1061-1073.

[75] Syme, C. D., Blanch, E. W., Holt, C., Jakes, R., Goedert, M., Hecht, L., and Barron, L. D. (2002) A Raman optical activity study of rheomorphism in caseins, synucleins and tau - New insight into the structure and behaviour of natively unfolded proteins, European Journal of Biochemistry 269, 148-156.

[76] Rucker, A. L., and Creamer, T. P. (2002) Polyproline II helical structure in protein unfolded states: Lysine peptides revisited, Protein Science 11, 980-985.

[77] Smyth, E., Syme, C. D., Blanch, E. W., Hecht, L., Vasak, M., and Barron, L. D. (2001) Solution structure of native proteins with irregular folds from Raman optical activity, Biopolymers 58, 138-151.

[78] Zhu, F. J., Isaacs, N. W., Hecht, L., and Barron, L. D. (2005) Raman optical activity: A tool for protein structure analysis, Structure 13, 1409-1419.

[79] Mensch, C., Konijnenberg, A., Van Elzen, R., Lambeir, A. M., Sobott, F., and Johannessen, C. (2017) Raman optical activity of human alpha-synuclein in intrinsically disordered, micelle-bound alpha-helical, molten globule and oligomeric beta-sheet state, Journal of Raman Spectroscopy 48, 910-918.

[80] Apetri, M. M., Maiti, N. C., Zagorski, M. G., Carey, P. R., and Anderson, V. E. (2006) Secondary structure of alpha-synuclein oligomers: Characterization by Raman and atomic force microscopy, Journal of Molecular Biology 355, 63-71.

[81] Palanisamy, S., Yan, L., Zhang, X., and He, T. (2015) Surface enhanced Raman scattering-active worm-like $\mathrm{Ag}$ clusters for sensitive and selective detection of dopamine, Analytical Methods 7, 3438-3447.

[82] Ranc, V., Markova, Z., Hajduch, M., Prucek, R., Kvitek, L., Kaslik, J., Safarova, K., and Zboril, R. (2014) Magnetically Assisted Surface-Enhanced Raman Scattering Selective Determination of Dopamine in an Artificial Cerebrospinal Fluid and a Mouse Striatum Using Fe3O4/Ag Nanocomposite, Analytical Chemistry 86, 2939-2946.

[83] Lim, J.-W., and Kang, I.-J. (2013) Chitosan-gold Nano Composite for Dopamine Analysis using Raman Scattering, Bulletin of the Korean Chemical Society 34, 237-242.

[84] Lim, J.-W., and Kang, I.-J. (2014) Fabrication of Chitosangold Nanocomposites Combined with Optical Fiber as SERS Substrates to Detect Dopamine Molecules, Bulletin of the Korean Chemical Society 35, 25-29.

[85] An, J.-H., El-Said, W. A., Yea, C.-H., Kim, T.-H., and Choi, J.-W. (2011) Surface-Enhanced Raman Scattering of Dopamine on Self-Assembled Gold Nanoparticles, Journal of Nanoscience and Nanotechnology 11, 44244429.

[86] Cheng, H. C., Ulane, C. M., and Burke, R. E. (2010) Clinical Progression in Parkinson Disease and the Neurobiology of Axons, Annals of Neurology 67, 715-725.

[87] Myers, R. H. (2004) Huntington's disease genetics, NeuroRx : the journal of the American Society for Experimental NeuroTherapeutics 1, 255-262.

[88] Paulsen, J. S. (2011) Cognitive Impairment in Huntington Disease: Diagnosis and Treatment, Current Neurology and Neuroscience Reports 11, 474-483.

[89] Masino, L., Kelly, G., Leonard, K., Trottier, Y., and Pastore, A. (2002) Solution structure of polyglutamine tracts in GST-polyglutamine fusion proteins, Febs Letters 513, 267-272.

[90] Chen, S., Berthelier, V., Yang, W., and Wetzel, R. (2001) Polyglutamine aggregation behavior in vitro supports a recruitment mechanism of cytotoxicity, Journal of Molecular Biology 311, 173-182.

[91] Walters, R. H., and Murphy, R. M. (2009) Examining Polyglutamine Peptide Length: A Connection between Collapsed Conformations and Increased Aggregation, Journal of Molecular Biology 393, 978-992.

[92] Crick, S. L., Jayaraman, M., Frieden, C., Wetzel, R., and Pappu, R. V. (2006) Fluorescence correlation spectroscopy shows that monomeric polyglutamine molecules form collapsed structures in aqueous solutions, Proceedings of the National Academy of Sciences of the United States of America 103, 1676416769.

[93] Chellgren, B. W., Miller, A.-F., and Creamer, T. P. (2006) Evidence for polyproline II helical structure in short polyglutamine tracts, Journal of Molecular Biology 361, 362-371.

[94] Wang, X. L., Vitalis, A., Wyczalkowski, M. A., and Pappu, R. V. (2006) Characterizing the conformational 
ensemble of monomeric polyglutamine, ProteinsStructure Function and Bioinformatics 63, 297-311.

[95] Xiong, K., Punihaole, D., and Asher, S. A. (2012) UV Resonance Raman Spectroscopy Monitors Polyglutamine Backbone and Side Chain Hydrogen Bonding and Fibrillization, Biochemistry 51, 58225830.

[96] Romeike, B. F. M., Meyer, T., Reichart, R., Kalff, R., Petersen, I., Dietzek, B., and Popp, J. (2015) Coherent anti-Stokes Raman scattering and two photon excited fluorescence for neurosurgery, Clinical Neurology and Neurosurgery 131, 42-46.

[97] Lu, F. K., Calligaris, D., Olubiyi, O. I., Norton, I., Yang, W. L., Santagata, S., Xie, X. S., Golby, A. J., and Agar, N. Y. R. (2016) Label-Free Neurosurgical Pathology with Stimulated Raman Imaging, Cancer Research 76, 34513462.

[98] Galli, R., Uckermann, O., Temme, A., Leipnitz, E., Meinhardt, M., Koch, E., Schackert, G., Steiner, G., and Kirsch, M. (2017) Assessing the efficacy of coherent anti-Stokes Raman scattering microscopy for the detection of infiltrating glioblastoma in fresh brain samples, Journal of Biophotonics 10, 404-414.

[99] Perney, N. M., Braddick, L., Jurna, M., Garbacik, E. T., Offerhaus, H. L., Serpell, L. C., Blanch, E., HoldenDye, L., Brocklesby, W. S., and Melvin, T. (2012) Polyglutamine Aggregate Structure In Vitro and In Vivo; New Avenues for Coherent Anti-Stokes Raman Scattering Microscopy, Plos One 7.

[100] Jermyn, M., Mok, K., Mercier, J., Desroches, J., Pichette, J., Saint-Arnaud, K., Bernstein, L., Guiot, M. C., Petrecca, K., and Leblond, F. (2015) Intraoperative brain cancer detection with Raman spectroscopy in humans, Science Translational Medicine 7.

[101] Huang, Y., and Mucke, L. (2012) Alzheimer Mechanisms and Therapeutic Strategies, Cell 148, 1204-1222.

[102] Miura, T., Suzuki, K., Kohata, N., and Takeuchi, H. (2000) Metal binding modes of Alzheimer's amyloid betapeptide in insoluble aggregates and soluble complexes, Biochemistry 39, 7024-7031.

[103] Miura, T., Suzuki, K., and Takeuchi, H. (2001) Binding of iron(III) to the single tyrosine residue of amyloid betapeptide probed by Raman spectroscopy, Journal of Molecular Structure 598, 79-84.

[104] Yugay, D., Goronzy, D. P., Kawakami, L. M., Claridge, S. K., Song, T. B., Yan, Z. B., Xie, Y. H., Gilles, J., Yang, Y., and Weiss, P. S. (2016) Copper Ion Binding Site in beta-Amyloid Peptide, Nano Letters 16, 6282-6289.

[105] Rivas-Arancibia, S., Rodriguez-Martinez, E., BadilloRamirez, I., Lopez-Gonzalez, U., and Saniger, J. M. (2017) Structural Changes of Amyloid Beta in Hippocampus of Rats Exposed to Ozone: A Raman Spectroscopy Study, Frontiers in Molecular Neuroscience 10.

[106] Bhowmik, D., Mote, K. R., MacLaughlin, C. M., Biswas, N., Chandra, B., Basu, J. K., Walker, G. C., Madhu, P. K., and Maiti, S. (2015) Cell-Membrane-Mimicking Lipid-Coated Nanoparticles Confer Raman Enhancement to Membrane Proteins and Reveal Membrane-Attached Amyloid-beta Conformation, ACS Nano 9, 9070-9077.

[107] Ghosh, C., Mukherjee, S., Seal, M., and Dey, S. G. (2016) Peroxidase to Cytochrome b Type Transition in the Active Site of Heme-Bound Amyloid beta Peptides Relevant to Alzheimer's Disease, Inorganic Chemistry $55,1748-1757$.
[108] Paul, T. J., Hoffmann, Z., Wang, C. Z., Shanmugasundaram, M., DeJoannis, J., Shekhtman, A., Lednev, I. K., Yadavalli, V. K., and Prabhakar, R. (2016) Structural and Mechanical Properties of Amyloid Beta Fibrils: A Combined Experimental and Theoretical Approach, Journal of Physical Chemistry Letters 7, 2758-2764.

[109] Xiong, J., and Jiji, R. D. (2017) Insights into the aggregation mechanism of A beta(25-40), Biophysical Chemistry 220, 42-48.

[110] Wang, M. J., and Jiji, R. D. (2011) Resolution of localized small molecule-A beta interactions by deep-ultraviolet resonance Raman spectroscopy, Biophysical Chemistry 158, 96-103.

[111] Hovmoller, S., Zhou, T., and Ohlson, T. (2002) Conformations of amino acids in proteins, Acta Crystallographica Section D-Biological Crystallography 58, 768-776.

[112] Kurouski, D., Van Duyne, R. P., and Lednev, I. K. (2015) Exploring the structure and formation mechanism of amyloid fibrils by Raman spectroscopy: a review, Analyst 140, 4967-4980.

[113] Tsuboi, M., Benevides, J. M., and Thomas, G. J. (2009) Raman Tensors and their application in structural studies of biological systems, Proceedings of the Japan Academy Series B-Physical and Biological Sciences 85, 83-97.

[114] Lekprasert, B., Korolkov, V., Falamas, A., Chis, V., Roberts, C. J., Tendler, S. J. B., and Notingher, I. (2012) Investigations of the Supramolecular Structure of Individual Diphenylalanine Nano- and Microtubes by Polarized Raman Microspectroscopy, Biomacromolecules 13, 2181-2187.

[115] Bhowmik, D., MacLaughlin, C. M., Chandrakesan, M., Ramesh, P., Venkatramani, R., Walker, G. C., and Maiti, S. (2014) pH changes the aggregation propensity of amyloid-beta without altering the monomer conformation, Physical Chemistry Chemical Physics 16, 885-889.

[116] Choi, I., Huh, Y. S., and Erickson, D. (2012) Ultrasensitive, label-free probing of the conformational characteristics of amyloid beta aggregates with a SERS active nanofluidic device, Microfluidics and Nanofluidics 12, 663-669.

[117] Lin, H., Bhatia, R., and Lal, R. (2001) Amyloid beta protein forms ion channels: implications for Alzheimer's disease pathophysiology, Faseb Journal 15, 2433-2444.

[118] Sudworth, C. D., Archer, J. K. J., and Mann, D. (2005) Near infrared Raman spectroscopy for alzheimer's disease detection, In Proceedings of the SPIE - The International Society for Optical Engineering, pp 586203-586201-586203-586203-586208.

[119] Chen, P., Shen, A., Zhao, W., Baek, S.-J., Yuan, H., and Hu, J. (2009) Raman signature from brain hippocampus could aid Alzheimer's disease diagnosis, Applied Optics 48, 4743-4748.

[120] Goldstein, L. E., Muffat, J. A., Cherny, R. A., Moir, R. D., Ericsson, M. H., Huang, X. D., Mavros, C., Coccia, J. A., Faget, K. Y., Fitch, K. A., Masters, C. L., Tanzi, R. E., Chylack, L. T., and Bush, A. I. (2003) Cytosolic beta-amyloid deposition and supranuclear cataracts in lenses from people with Alzheimer's disease, Lancet 361, 1258-1265.

[121] Michael, R., Otto, C., Lenferink, A., Gelpi, E., Montenegro, G. A., Rosandic, J., Tresserra, F., Barraquer, R. I., and Vrensen, G. F. J. M. (2014) Absence of amyloid-beta in lenses of Alzheimer patients: A confocal Raman 
microspectroscopic study, Experimental Eye Research 119, 44-53.

[122] Michael, R., Rosandic, J., Montenegro, G. A., Lobato, E., Tresserra, F., Barraquer, R. I., and Vrensen, G. F. J. M. (2013) Absence of beta-amyloid in cortical cataracts of donors with and without Alzheimer's disease, Experimental Eye Research 106, 5-13.

[123] Catricala, S., Torti, M., and Ricevuti, G. (2012) Alzheimer disease and platelets: how's that relevant, Immunity \&amp; Ageing 9.

[124] Colciaghi, F., Borroni, B., Pastorino, L., Marcello, E., Zimmermann, M., Cattabeni, F., Padovani, A., and Di Luca, M. (2002) alpha-secretase ADAM10 as well as alpha APPs is reduced in platelets and CSF of Alzheimer disease patients, Molecular Medicine 8, 6774.

[125] Colciaghi, F., Marcello, E., Borroni, B., Zimmermann, M., Caltagirone, C., Cattabeni, F., Padovani, A., and Di Luca, M. (2004) Platelet APP, ADAM 10 and BACE alterations in the early stages of Alzheimer disease, Neurology 62, 498-501.

[126] Chen, P., Tian, Q., Baek, S. J., Shang, X. L., Park, A., Liu, Z. C., Yao, X. Q., Wang, J. Z., Wang, X. H., Cheng, Y., Peng, J., Shen, A. G., and Hu, J. M. (2011) Laser Raman detection of platelet as a non-invasive approach for early and differential diagnosis of Alzheimer's disease, Laser Physics Letters 8, 547-552.

[127] Carmona, P., Molina, M., Calero, M., Bermejo-Pareja, F., Martinez-Martin, P., and Toledanog, A. (2013) Discrimination Analysis of Blood Plasma Associated with Alzheimer's Disease Using Vibrational Spectroscopy, Journal of Alzheimers Disease 34, 911920.

[128] Hajian-Tilaki, K. (2013) Receiver Operating Characteristic (ROC) Curve Analysis for Medical Diagnostic Test Evaluation, Caspian journal of internal medicine 4, 627-635.

[129] Ryzhikova, E., Kazakov, O., Halamkova, L., Celmins, D., Malone, P., Molho, E., Zimmerman, E. A., and Lednev, I. K. (2015) Raman spectroscopy of blood serum for Alzheimer's disease diagnostics: specificity relative to other types of dementia, Journal of Biophotonics 8, 584-596.

[130] Beier, H. T., Cowan, C. B., Chou, I. H., Pallikal, J., Henry, J. E., Benford, M. E., Jackson, J. B., Good, T. A., and Cote, G. L. (2007) Application of surface-enhanced Raman spectroscopy for detection of beta amyloid using nanoshells, Plasmonics 2, 55-64.

[131] Beier, H. T., Cowan, C. B., Good, T. A., and Cote, G. L. (2008) A surface enhanced Raman spectroscopy platform based on nanoshells for detection of betaamyloid, In Plasmonics in Biology and Medicine $V$ (VoDinh, T., and Lakowicz, J. R., Eds.).

[132] Voiciuk, V., Valincius, G., Budvytyte, R., Matijoska, A., Matulaitiene, I., and Niaura, G. (2012) Surfaceenhanced Raman spectroscopy for detection of toxic amyloid beta oligomers adsorbed on self-assembled monolayers, Spectrochimica Acta Part a-Molecular and Biomolecular Spectroscopy 95, 526-532.

[133] Guerrini, L., Arenal, R., Mannini, B., Chiti, F., Pini, R., Matteini, P., and Alvarez-Puebla, R. A. (2015) SERS Detection of Amyloid Oligomers on MetallorganicDecorated Plasmonic Beads, ACS Applied Materials \&amp; Interfaces 7, 9420-9428.

[134] Tiwari, V. S., Khetani, A., Monfared, A. M. T., Smith, B., Anis, H., and Trudeau, V. L. (2012) Detection of amino acid neurotransmitters by surface enhanced Raman scattering and hollow core photonic crystal fiber, In Conference on Reporters, Markers, Dyes, Nanoparticles, and Molecular Probes for Biomedical Applications IV, San Francisco, CA.

[135] Monfared, A. M. T., Tiwari, V. S., Trudeau, V. L., and Anis, H. (2015) Surface-Enhanced Raman Scattering Spectroscopy for the Detection of Glutamate and gamma-Aminobutyric Acid in Serum by Partial Least Squares Analysis, Ieee Photonics Journal 7.

[136] Park, S. G., Ahn, M. S., Oh, Y. J., Kang, M., Jeong, Y., and Jeong, K. H. (2014) Nanoplasmonic Biopatch for in vivo Surface Enhanced Raman Spectroscopy, Biochip Journal 8, 289-294.

[137] Castro, J. L., SanchezCortes, S., Ramos, J. V. G., Otero, J. C., and Marcos, J. I. (1997) Surface-enhanced Raman spectroscopy of gamma-aminobutyric acid on silver colloid surfaces, Biospectroscopy 3, 449-455.

[138] Kuroda, H. (1983) Gamma-aminobutyric acid (GABA) in cerebrospinal-fluid, Acta Medica Okayama 37, 167-177.

[139] Buividas, R., Dzingelevicius, N., Kubiliute, R., Stoddart, P. R., Vi Khanh, T., Ivanova, E. P., and Juodkazis, S. (2015) Statistically quantified measurement of an Alzheimer's marker by surface-enhanced Raman scattering, Journal of Biophotonics 8, 567-574.

[140] El-Said, W. A., Kim, T.-H., Yea, C.-H., Kim, H., and Choi, J.-W. (2011) Fabrication of Gold Nanoparticle Modified ITO Substrate to Detect beta-Amyloid Using SurfaceEnhanced Raman Scattering, Journal of Nanoscience and Nanotechnology 11, 768-772.

[141] Zengin, A., Tamer, U., and Caykara, T. (2013) A SERSBased Sandwich Assay for Ultrasensitive and Selective Detection of Alzheimer's Tau Protein, Biomacromolecules 14, 3001-3009.

[142] Demeritte, T., Nellore, B. P. V., Kanchanapally, R., Sinha, S. S., Pramanik, A., Chavva, S. R., and Ray, P. C. (2015) Hybrid Graphene Oxide Based PlasmonicMagnetic Multifunctional Nanoplatform for Selective Separation and Label-Free Identification of Alzheimer's Disease Biomarkers, ACS Applied Materials \&amp; Interfaces 7, 13693-13700.

[143] Lim, W. L. F., Martins, I. J., and Martins, R. N. (2014) The Involvement of Lipids in Alzheimer's Disease, Journal of Genetics and Genomics 41, 261-274.

[144] Martins, I. C., Kuperstein, I., Wilkinson, H., Maes, E., Vanbrabant, M., Jonckheere, W., Van Gelder, P., Hartmann, D., D'Hooge, R., De Strooper, B., Schymkowitz, J., and Rousseau, F. (2008) Lipids revert inert A beta amyloid fibrils to neurotoxic protofibrils that affect learning in mice, Embo Journal 27, 224-233.

[145] Mudher, A., Shepherd, D., Newman, T. A., Mildren, P., Jukes, J. P., Squire, A., Mears, A., Berg, S., MacKay, D., Asuni, A. A., Bhat, R., and Lovestone, S. (2004) GSK-3 beta inhibition reverses axonal transport defects and behavioural phenotypes in Drosophila, Molecular Psychiatry 9, 522-530.

[146] Cowan, C. M., and Mudher, A. (2013) Are tau aggregates toxic or protective in tauopathies?, Frontiers in Neurology 4.

[147] Goedert, M. (2016) The ordered assembly of tau is the gainof-toxic function that causes human tauopathies, Alzheimers \& Dementia 12, 1040-1050.

[148] Wang, Y., and Mandelkow, E. (2016) Tau in physiology and pathology, Nature Reviews Neuroscience 17, 5-21.

[149] Ramachandran, G., Milan-Garces, E. A., Udgaonkar, J. B., and Puranik, M. (2014) Resonance Raman Spectroscopic Measurements Delineate the Structural 
Changes that Occur during Tau Fibril Formation, Biochemistry.

[150] Sanders, D. W., Kaufman, S. K., DeVos, S. L., Sharma, A. M., Mirbaha, H., Li, A. M., Barker, S. J., Foley, A. C., Thorpe, J. R., Serpell, L. C., Miller, T. M., Grinberg, L. T., Seeley, W. W., and Diamond, M. I. (2014) Distinct Tau Prion Strains Propagate in Cells and Mice and Define Different Tauopathies, Neuron 82, 1271-1288.

[151] Stopschinski, B. E., and Diamond, M. I. (2017) The prion model for progression and diversity of neurodegenerative diseases, Lancet Neurology 16, 323332.

[152] Holmes, B. B., Furman, J. L., Mahan, T. E., Yamasaki, T. R., Mirbaha, H., Eades, W. C., Belaygorod, L., Cairns, N. J., Holtzman, D. M., and Diamond, M. I. (2014) Proteopathic tau seeding predicts tauopathy in vivo, Proceedings of the National Academy of Sciences of the United States of America 111, E4376-E4385.

[153] Sawaya, M. R., Sambashivan, S., Nelson, R., Ivanova, M. I., Sievers, S. A., Apostol, M. I., Thompson, M. J., Balbirnie, M., Wiltzius, J. J. W., McFarlane, H. T., Madsen, A. O., Riekel, C., and Eisenberg, D. (2007) Atomic structures of amyloid cross-beta spines reveal varied steric zippers, Nature 447, 453-457.

[154] Clavaguera, F., Lavenir, I., Falcon, B., Frank, S., Goedert, M., and Tolnay, M. (2013) "Prion-Like" Templated Misfolding in Tauopathies, Brain Pathology 23, 342349.
[155] Clavaguera, F., Hench, J., Goedert, M., and Tolnay, M. (2015) Prion-like transmission and spreading of tau pathology, Neuropathology and Applied Neurobiology 41, 47-58.

[156] Goedert, M., and Spillantini, M. G. (2017) Propagation of Tau aggregates, Molecular Brain 10.

[157] Ashton, L., Johannessen, C., and Goodacre, R. (2011) The Importance of Protonation in the Investigation of Protein Phosphorylation Using Raman Spectroscopy and Raman Optical Activity, Analytical Chemistry 83, 7978-7983.

[158] Jarvis, R. M., Blanch, E. W., Golovanov, A. P., Screen, J., and Goodacre, R. (2007) Quantification of casein phosphorylation with conformational interpretation using Raman spectroscopy, Analyst 132, 1053-1060.

[159] Paraskevaidi, M., Morais, C. L. M., Lima, K. M. G., Snowden, J. S., Saxon, J. A., Richardson, A. M. T., Jones, M., Mann, D. M. A., Allsop, D., Martin-Hirsch, P. L., and Martin, F. L. (2017) Differential diagnosis of Alzheimer's disease using spectrochemical analysis of blood, Proceedings of the National Academy of Sciences of the United States of America 114, E7929E7938. 